\title{
Early-Stage Recovery of Lithium from Tailored Thermal Conditioned Black Mass Part I: Mobilizing Lithium via Supercritical $\mathrm{CO}_{2}$-Carbonation
}

\author{
Lilian Schwich *, Tom Schubert and Bernd Friedrich (D)
}

Citation: Schwich, L.; Schubert, T.; Friedrich, B. Early-Stage Recovery of Lithium from Tailored Thermal Conditioned Black Mass Part I: Mobilizing Lithium via Supercritical $\mathrm{CO}_{2}$-Carbonation. Metals 2021, 11 , 177. https://doi.org/10.3390/met 11020177

Received: 19 November 2020

Accepted: 18 January 2021

Published: 20 January 2021

Publisher's Note: MDPI stays neutral with regard to jurisdictional claims in published maps and institutional affiliations.

Copyright: (c) 2021 by the authors. Licensee MDPI, Basel, Switzerland. This article is an open access article distributed under the terms and conditions of the Creative Commons Attribution (CC BY) license (https:// creativecommons.org/licenses/by/ $4.0 /)$.
IME, Institute for Process Metallurgy and Metal Recycling, RWTH Aachen University, 52056 Aachen, Germany; tom.schubert@rwth-aachen.de (T.S.); bfriedrich@ime-aachen.de (B.F.)

* Correspondence: lschwich@ime-aachen.de; Tel.: +49-2418-095-194

Abstract: In the frame of global demand for electrical storage based on lithium-ion batteries (LIBs), their recycling with a focus on the circular economy is a critical topic. In terms of political incentives, the European legislative is currently under revision. Most industrial recycling processes target valuable battery components, such as nickel and cobalt, but do not focus on lithium recovery. Especially in the context of reduced cobalt shares in the battery cathodes, it is important to investigate environmentally friendly and economic and robust recycling processes to ensure lithium mobilization. In this study, the method early-stage lithium recovery ("ESLR") is studied in detail. Its concept comprises the shifting of lithium recovery to the beginning of the chemo-metallurgical part of the recycling process chain in comparison to the state-of-the-art. In detail, full NCM (Lithium Nickel Manganese Cobalt Oxide)-based electric vehicle cells are thermally treated to recover heat-treated black mass. Then, the heat-treated black mass is subjected to an $\mathrm{H}_{2} \mathrm{O}$-leaching step to examine the share of water-soluble lithium phases. This is compared to a carbonation treatment with supercritical $\mathrm{CO}_{2}$, where a higher extent of lithium from the heat-treated black mass can be transferred to an aqueous solution than just by $\mathrm{H}_{2} \mathrm{O}$-leaching. Key influencing factors on the lithium yield are the filter cake purification, the lithium separation method, the solid/liquid ratio, the pyrolysis temperature and atmosphere, and the setup of autoclave carbonation, which can be performed in an $\mathrm{H}_{2} \mathrm{O}$-environment or in a dry autoclave environment. The carbonation treatments in this study are reached by an autoclave reactor working with $\mathrm{CO}_{2}$ in a supercritical state. This enables selective leaching of lithium in $\mathrm{H}_{2} \mathrm{O}$ followed by a subsequent thermally induced precipitation as lithium carbonate. In this approach, treatment with supercritical $\mathrm{CO}_{2}$ in an autoclave reactor leads to lithium yields of up to $79 \%$.

Keywords: battery recycling; lithium-ion batteries; metallurgical recycling; metal recovery; recycling efficiency; carbonation; lithium phase transformation; autoclave; supercritical $\mathrm{CO}_{2}$

\section{Introduction}

The need for lithium recovery from LIBs is a crucial topic in terms of increased electromobility since lithium is and will remain a relevant element also in next-generation batteries. Lithium is currently industrially, not recycled. Hydrometallurgical research focuses on recovering lithium at the end of the processes; thus, impurities from process additives are possible, and moreover, reagents like $\mathrm{Na}_{2} \mathrm{CO}_{3}$ are needed for generating a marketable lithium product. The present study aims to present a method to mobilize lithium without using expensive or environmentally harmful additives: The early-stage lithium recovery ("ESLR") method. This "ESLR" particularly requires a suitable thermal pretreatment, and other elements can then be integrated into existing metal refining processes. The full "ESLR" process investigated here are shown in Figure 1.

For this research's purpose, the publication is structured into three parts: first, state-ofthe-art processes for LIBs recycling are contrasted to innovative research for lithium phase 
transformation. Second, our own research results based on experimental studies are presented and subsequently evaluated in terms of lithium yield and purity. Concludingly, the obtained results are discussed by showing their scientific findings and process technology relevance in comparison to the state-of-the-art.

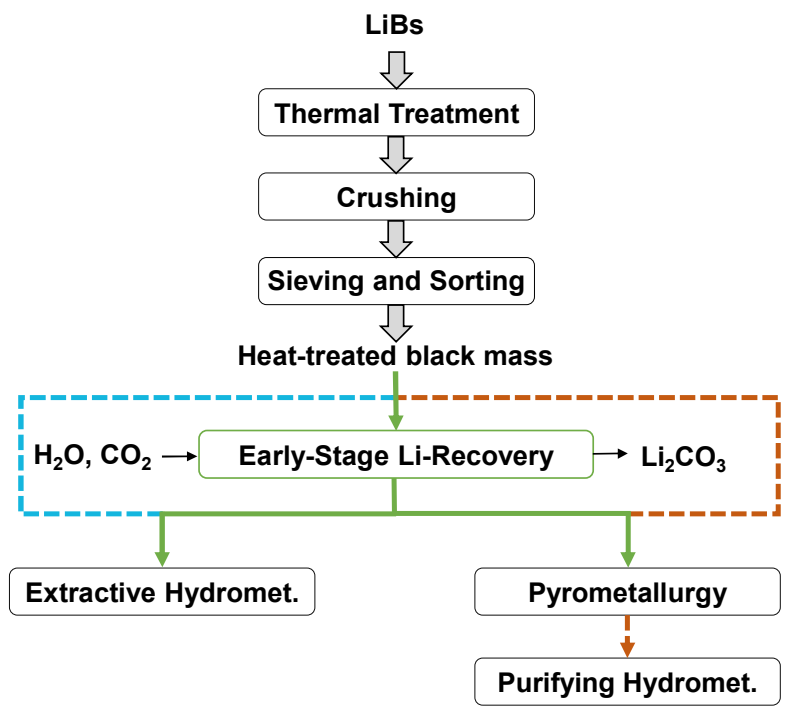

\section{Anticipated benefits of "ESLR"}

- No chemicals required

- No carbonation agent impurities like Na oder K in Li-product

- Comparing to hydrometallurgy: Less leaching agents due to reduced mass

- Comparing to direct pyrometallurgy with purifying hydrometallurgy: Less energy needed

Figure 1. General flowchart of the early stage Li-recovery discussed in this study and the process benefits at a glance.

\subsection{State-of-the-Art in Recycling Li-ion Batteries}

LIBs recycling comprises different modules and sequences, leading to alternative process paths. Statements regarding future-dominant process pathways are afflicted with uncertainties due to location and know-how aspects and also because of the heterogeneous and changing scrap stream compositions [1]. However, the available processes, until the point of having generated marketable products, can be divided into preconditioning and metallurgical extraction [2]. The pretreatment steps, in turn, can be asserted to different sectors: deactivation/discharging [3], mechanical processing as dismantling of EV modules and packs to cell level, comminution and sorting by size or physical properties [4] and finally a thermal treatment [5]. Within the metallurgical techniques, there are mainly hydro- and pyrometallurgical processes available [6]. They both comprise benefits and drawbacks; for example, in hydrometallurgy also ignoble elements, like Fe, $\mathrm{Al}$ and $\mathrm{C}$, can be recovered, but on the other hand, the processing goes along with comparatively slow kinetics [6]. Depending on individual core objectives, the cells can be charged into a smelter without any pretreatment [3], but regarding a circular economy approach, it is beneficial to consider pretreatment steps [7] in order to maximize resource efficiency. Besides conventional industrial treatments, different studies are in place to give an overview also on innovative emerging recycling paths [8,9] and also approaches to evaluate the environmental impacts of different paths [10-12]. First, the available processes for recycling $\mathrm{Li}$-ion batteries are described, and second, innovative processes for $\mathrm{CO}_{2}$-promoted lithium phase transformations are shown. Therefore, first, indirect carbonation principles and studies are outlined, second, literature on direct carbonation is presented and third, the role of $\mathrm{CO}_{2}$ in a supercritical state is pointed out. Goal of this detailed elaboration is a monitoring of gaps in literature regarding efficient lithium recovery from LIBs.

\subsubsection{Thermal Preconditioning}

Thermal pretreatments can be carried out, for example, as pyrolysis. Here, the cells are deactivated in the absence of oxygen at temperatures of typically $600{ }^{\circ} \mathrm{C}$ [13]. Pyrolysis (as well as classical incineration) are thermal pretreatments allowing for a safe cell deactivating and facilitating further downstream recycling without risking a so-called thermal runaway $[14,15]$. Through chemical cracking and such removal as organic compounds 
in gaseous form, which originate primarily from binder, electrolyte, and separator, takes place $[13,16]$. A major advantage of thermal treatments comprises a safe cell deactivating, thus contributing to risk mitigation in the context of fire incidents. This thermal runaway can occur, for example, during scrap transport, storing, but also by mechanical processing due to this mechanical, electrical or thermal abuse [17]. Several studies report the second advantage of thermal pretreatments, namely an improved detaching of black mass from the cell's current collector foils [7,16,18-21]. Additionally, suitable mechanical preconditioning concepts are required for efficient downstream processing, especially for hydrometallurgical treatments [3]. A mechanical process consists of comminution and sorting for splitting black mass and other cell components, such as casing and current collector foils. Hence, by subsequent mechanical postprocessing, aluminum and copper foils, along with the metallic casing, either aluminum or steel, can be separated as marketable products from the black mass. Black mass then contains all electrochemical active electrode materials [22]. Due to different battery systems on the market, black mass always has different chemical compositions [22].

The separation into individual fractions by means of sieving or physical separation techniques contributes to higher yields of the valuable components and, finally, increases process recycling efficiency [14]. In this way, copper, aluminum and steel can be integrated into their specific recycling processes. Regarding the extracted black mass, two processing alternatives are in place: hydrometallurgical and pyrometallurgical treatments. In the following, these two methods and their challenges for lithium recycling are compared.

1.1.2. Lithium Behavior in Pyro- and Hydrometallurgical Recycling Steps and Need for Early-Stage Li-Separation

Smelting of possibly pelletized black mass with the addition of $\mathrm{SiO}_{2}$ as slag additive in an electric arc furnace has shown that lithium accumulates both in slag and flue dust [23]. Due to its ignoble character, extraction via a metal phase is not possible. As can be seen in Figure 2, a negligible proportion of approximately $0.35 \%$ of lithium is accounted for in the alloy produced. Depending on the selected slag system and the amount of slag, increased accumulation in the slag or flying dust can be realized (see Figure 2). Since the slag has a solubility limit for lithium oxide, according to Vest [24], the evaporation of lithium takes place when the corresponding concentration is exceeded. Due to re-oxidation processes, lithium oxide is accumulated in the flue dust (see Figure 2 below, according to Vest [24]). When operating at the lab-scale, smaller quantities of slag are generated, leading to a larger proportion of lithium transferred to the flue dust. The two Sankey diagrams in Figure 2 show a broad distribution of lithium between the three phases slag, flue dust and partly alloy, which is valid for both smelting setups. In order to extract lithium from the produced slag, energy-intensive crushing, classifying and hydrometallurgical purifying are required, but the costs for these treatment steps are currently not covered by lithium's raw material price [3]. 


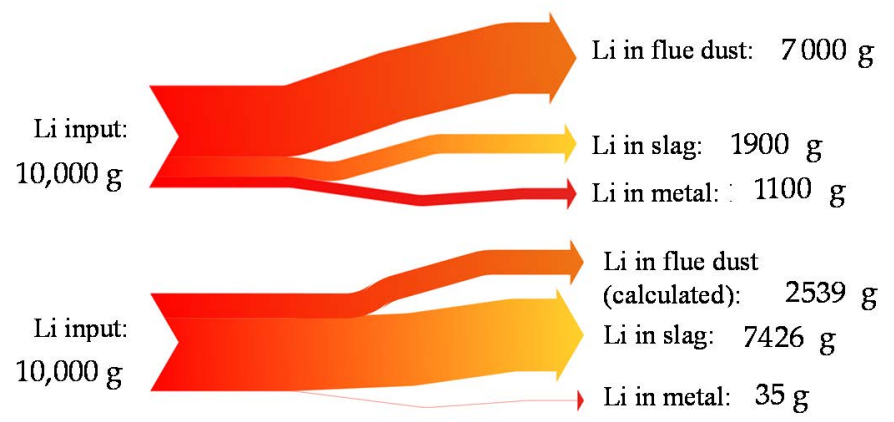

Figure 2. Lithium distribution after the smelting of black mass in an electric arc furnace. Above: process design aiming for a lithium enrichment in flue dust, based on [23,24]. Below: process design aiming for a lithium enrichment in slag [23]. Reproduced with permission from Stallmeister, C., Schwich, L. and Friedrich, B., Early-Stage Li-Removal-Vermeidung von Lithiumverlusten im Zuge der Thermischen und Chemischen Recyclingrouten von Batterien; published by Thomé-Kozmiensky Verlag GmbH, 2020.

When treating the extracted black mass by hydrometallurgical processing, lithium is not always enriched in one single product fraction, neither, but can be distributed during the multi-step precipitation series in all filter cakes [25]. Firstly, a black mass is typically leached in mineral acid. For this purpose, it is beneficial to conduct the thermal pretreatment as described easing the dissolution process [26]. Here, Shin et al. report the binder's (polyvinylidene fluoride, PVDF) property of not dissolving in acidic solution and disturbing the filtration process after leaching [27]. Yang et al. have shown a strategy to separately incinerate and then hydrometallurgically treat spent anode material in order to purify the C-fraction from lithium impurities, recovering lithium by means of $\mathrm{Na}_{2} \mathrm{CO}_{3}$ [28]. When treating the black mass from both cathode and anode, the target products such as copper, iron and aluminum, cobalt, nickel and manganese are cemented or precipitated one after the other. Lithium salt recovery, e.g., as carbonate $\left(\mathrm{Li}_{2} \mathrm{CO}_{3}\right)$, is the last process step in the hydrometallurgical process chain, as suggested by Wang et al. [25]. Wang et al. have proven a lithium leaching efficiency of $98.5 \%$ [25]. For obtaining $\mathrm{Li}_{2} \mathrm{CO}_{3}$ in the last process step, a carbonation additive like sodium carbonate is used. During the precipitation stages, as can be seen from the data in Figure 3, approx. 27\% of lithium remains in other filter cakes. Thus, the purity of the obtained copper, $\mathrm{Fe} / \mathrm{Al}$ and Ni-Co products is reduced, and the yield of recovered lithium suffers. Moreover, a share of lithium remains in wastewater leading to a complex circuit with continuous neutralization salt removal, again including lithium losses. This complex processing is up to now industrially only viable by recovering the valuable metals nickel, copper and cobalt [3].

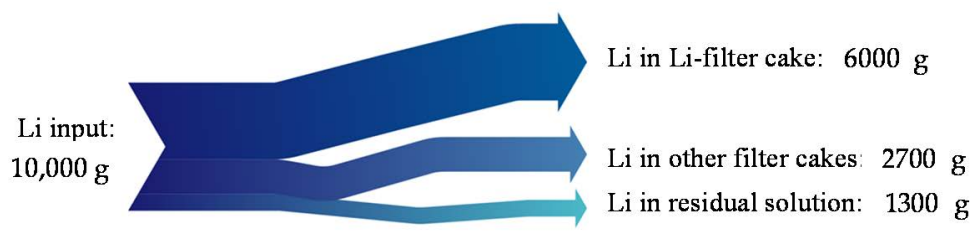

Figure 3. Lithium distribution after leaching trials of extracted black mass (current trials at IME), based on [23] (data used in [23] was based on experiments by Wang et al. [25]). Reproduced with permission from Stallmeister, C., Schwich, L. and Friedrich, B., Early-Stage Li-Removal-Vermeidung von Lithiumverlusten im Zuge der Thermischen und Chemischen Recyclingrouten von Batterien; published by Thomé-Kozmiensky Verlag GmbH, 2020.

Hence, the process's bottleneck lies in lithium extraction as a solid product instead of lithium leachability (leaching efficiency). A wide range of hydrometallurgical studies shows high leaching efficiencies using different solvents [29-34], for example, by using 
$\mathrm{H}_{2} \mathrm{SO}_{4}$, a lithium leaching efficiency of $96.7 \%$ [35], and by $\mathrm{HCl} 99.2 \%$ [36]. In [37], leaching in citric acid and precipitating lithium by sodium phosphate leads to a leaching efficiency of $99 \% \mathrm{Li}$ and a recovery as $\mathrm{Li}_{3} \mathrm{PO}_{4}$ of $89 \%$. In [38-41] also a lithium precipitation of solid $\mathrm{Li}_{2} \mathrm{CO}_{3}$ by $\mathrm{Na}_{2} \mathrm{CO}_{3}$ is reported, reaching yields of $80 \%$ [38], $90 \%$ [39] and $99 \%$ [40]. In [38], a corresponding purity of $96.97 \%$ is reached; in [39], no purity is given; in [40], the lithium filter cake consists of $10.13 \mathrm{wt} . \% \mathrm{Li}$. With a molar ratio of $\mathrm{Li} / \mathrm{Li}_{2} \mathrm{CO}_{3}=18.79 \%$, this would mean a $\mathrm{Li}_{2} \mathrm{CO}_{3}$ content of $53.91 \%$, assuming $10.31 \mathrm{wt}$ \% exists as pure $\mathrm{Li}_{2} \mathrm{CO}_{3}$. When using cathode black mass only, a recovery of $\mathrm{Li}$ as $\mathrm{Li}_{2} \mathrm{CO}_{3}$ of $98.22 \%$ with a purity of $99.9 \%$ is reported [41]. This means that reaching both a high $\mathrm{Li}_{2} \mathrm{CO}_{3}$ purity with a high yield is not straightforward but achievable. Nonetheless, lithium recovery always requires additives, which can be avoided by direct $\mathrm{H}_{2} \mathrm{O}$-leaching. Moreover, the volume of required leaching agents can be lowered by $\mathrm{H}_{2} \mathrm{O}$-leaching before entering conventional hydrometallurgy due to a mass reduction. In this study, $\mathrm{H}_{2} \mathrm{O}$-leaching and using supercritical $\mathrm{CO}_{2}$ are assessed for environmentally friendly and additive-free lithium recovery.

\subsubsection{Liquid-Gas Carbonation (Indirect Carbonation)}

The hypothesis of this work is a mobilizing of lithium by an "Early-Stage Li-Recovery". Different methods may be applied for this phase transformation to Li-carbonate, which are addressed in the following paragraphs. The use of $\mathrm{CO}_{2}$ for carbonation purposes has been examined for non-lithium materials in numerous studies, e.g., [42-45], and even treating of battery materials with $\mathrm{CO}_{2}$ is possible, as shown above by Hu et al. and Zhang et al. [46,47]. Generally, Kunzler et al. investigated the parameters influencing indirect carbonation, which is understood as a reaction between dissolved elements and $\mathrm{CO}_{2}$. In contrast to that, direct carbonation is defined as a gas-solid reaction for generating carbonates [48]. Kunzler et al. found a correlation between extraction efficiency and grain size of the target metals, solid to liquid ratio, concentration and hence $\mathrm{pH}$ value of the leaching agent, and temperature [48].

When aiming for indirect $\mathrm{CO}_{2}$-driven reactions, $\mathrm{Hu}$ et al. have conducted a combination of a reductive thermal treatment and $\mathrm{H}_{2} \mathrm{O}$-leaching in combination with $\mathrm{CO}_{2}$-gas [46]. Here, only cathode material from NMC (Lithium Nickel Manganese Cobalt Oxide)-cells was mixed with lignite as a reducing agent. According to the maximum reported leaching efficiency of $85 \%$ for $\mathrm{Li}$, the optimal thermal-treatment temperature is at $650{ }^{\circ} \mathrm{C}$, and the optimal s/l ratio is $10 \mathrm{~mL} / \mathrm{g}(1: 10(\mathrm{~g} / \mathrm{mL}))$. Zhang et al. have developed this study further using the same parameters but also investigating optimal $\mathrm{CO}_{2}$ flow rate and leaching time, leading to a Li-recovery of $85 \%$ [47]. In summary, when treating the cathode mass only and adding reducing agents like lignite or carbon black to the thermal treatment, lithium yields of $85 \%$ [46,47]. However, if not applying $\mathrm{CO}_{2}$ during leaching, the leaching efficiency of lithium is $40 \%[46,47]$. This indicates that the mechanism of indirect carbonation is decisive, but in [46,47], no $\mathrm{CO}_{2}$ atmosphere was used during the thermal treatment; instead, a solid C-carrier was added.

A similar approach is pursued by Jandová et al., where a lithium-containing solution, not stemming from batteries, is treated with $\mathrm{CO}_{2}$ [49]. Then, the solution is heated until the lithium concentration reaches $12-13 \mathrm{~g} / \mathrm{L}$, and afterward treated with $\mathrm{CO}_{2}$-gas at a temperature of $40{ }^{\circ} \mathrm{C}$ for $2 \mathrm{~h}$ to generate $\mathrm{LiHCO}_{3}$. Lithium hydrogen carbonate provides a higher solubility in comparison to the first, formed $\mathrm{Li}_{2} \mathrm{CO}_{3}$. Finally, the lithium solution is boiled to produce $\mathrm{Li}_{2} \mathrm{CO}_{3}[46,47,49]$. Moreover, an indirect carbonation approach for non-battery materials gives insights into general mechanisms when purging $\mathrm{CO}_{2}$ into aqueous solutions [45]. Within these aqueous treatments, $\mathrm{CO}_{2}$ dissolves as [45,50]:

$$
\mathrm{CO}_{2}+\mathrm{H}_{2} \mathrm{O} \leftrightarrow \mathrm{H}_{2} \mathrm{CO}_{3} \leftrightarrow \mathrm{H}^{+}+\mathrm{HCO}_{3}^{-} \leftrightarrow \mathrm{CO}_{3}^{2-}+2 \mathrm{H}^{+}
$$

The more $\mathrm{H}$-cations are released, the stronger is the resulting acidification [50]. These reactions are to be understood as a function of temperature, pressure and $\mathrm{pH}$ [45]. With increasing $\mathrm{pH}$, the dominantly existing phases alternate in the following sequence: $\mathrm{H}_{2} \mathrm{CO}_{3}$, $\mathrm{HCO}_{3}^{-}$and $\mathrm{CO}_{3}^{2-}$, hence the higher the $\mathrm{pH}$-value, the more $\mathrm{H}^{+}$-ions are released, contribut- 
ing to a lowered $\mathrm{pH}$. Especially, $\mathrm{CO}_{3}^{2-}$ is dominant in a $\mathrm{pH}$-area of 10 onwards, whereas $\mathrm{HCO}_{3}^{-}$is dominant in an area from 6 to 9 , as can be seen in Figure 4:

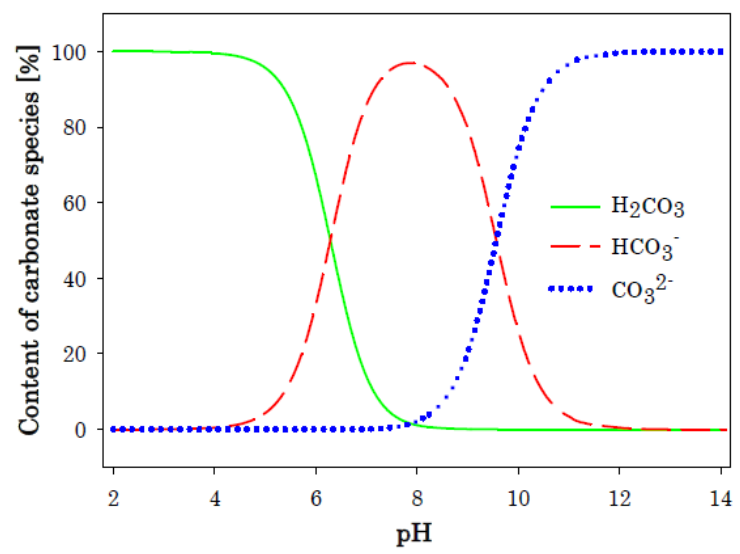

Figure 4. Available $\mathrm{CO}_{2}$-based phases in aqueous solution over the $\mathrm{pH}$ [45]. Reproduced with permission from Haug, T. A., Dissolution and carbonation of mechanically activated olivine-Investigating $\mathrm{CO}_{2}$ sequestration possibilities; published by Haug, T.A., 2010.

A reaction between $\mathrm{HCO}_{3}^{-} / \mathrm{CO}_{3}^{2-}$ and lithium requires the presence of $\mathrm{Li}^{+}$in the solution. In Table 1, possible lithium phases and their solubility is presented. Connected to that, the chemical reaction formula is presented describing the dissolution of lithium phases in an aqueous solution, without and with $\mathrm{CO}_{2}$-gas purging.

Table 1. Solubility of selected lithium phases at 20 and $100{ }^{\circ} \mathrm{C}$.

\begin{tabular}{ccc}
\hline Phase & Solubility at $\mathbf{2 0}{ }^{\circ} \mathbf{C}$ & Solubility at $\mathbf{1 0 0}{ }^{\circ} \mathbf{C}$ \\
\hline $\mathrm{LiOH}$ & $110 \mathrm{~g} / \mathrm{L}^{1}$ & $161 \mathrm{~g} / \mathrm{L}^{1}$ \\
$\mathrm{LiF}$ & $1.2 \mathrm{~g} / \mathrm{L}^{1}$ & $1.34 \mathrm{~g} / \mathrm{L}^{1}$ \\
$\mathrm{LiHCO}_{3}$ & $55 \mathrm{~g} / \mathrm{L}^{2}$ & $57.4 \mathrm{~g} / \mathrm{L}^{1}$ \\
$\mathrm{Li}_{2} \mathrm{CO}_{3}$ & $13.3 \mathrm{~g} / \mathrm{L}^{1}$ & $7.2 \mathrm{~g} / \mathrm{L}^{1}$ \\
\hline
\end{tabular}

${ }^{1}[51],{ }^{2}[52]$ at $18{ }^{\circ} \mathrm{C}$.

Yi et al. have also reported the conversion from $\mathrm{Li}_{2} \mathrm{CO}_{3}$ in aqueous solution into $\mathrm{LiHCO}_{3}$ by $\mathrm{CO}_{2}$-based carbonation, followed by a chemical purification of the solution and subsequent crystallization of $\mathrm{Li}_{2} \mathrm{CO}_{3}$ from a $\mathrm{LiHCO}_{3}$ solution by boiling [53].

If lithium is present as $\mathrm{Li}_{2} \mathrm{CO}_{3}$, it decomposes according to Equation (2) [54]:

$$
\mathrm{Li}_{2} \mathrm{CO}_{3} \leftrightarrow \mathrm{Li}^{+}{ }_{(\mathrm{aq})}+\mathrm{CO}_{3}{ }^{2-}{ }_{(\mathrm{aq})}
$$

The carbonate ion $\left(\mathrm{CO}_{3}{ }^{2-}\right.$ (aq) $)$ is the conjugate base of a weak acid (carbonic acid) [55]. Hence, $\mathrm{H}^{+}$-ions are attracted at neutral or acidic areas and consumed from $\mathrm{H}_{2} \mathrm{O}$, which generally is present in the ionic form [55-57]. This chemical behavior equals the property of $\mathrm{Li}_{2} \mathrm{CO}_{3}$ to be alkaline (see Equation (7)) [58]. In combination with $\mathrm{CO}_{2}$-gas, Yi et al. also report the chemical steps between $\mathrm{Li}_{2} \mathrm{CO}_{3}$ dissolution consuming $\mathrm{H}^{+}$-ions from the $\mathrm{H}_{2} \mathrm{CO}_{3}$-decomposition (see Equation (3)) [53] and precipitation of solid $\mathrm{Li}_{2} \mathrm{CO}_{3}$ according to Equation (4) to Equation (7) [53]:

$$
\begin{aligned}
\mathrm{CO}_{2}+\mathrm{H}_{2} \mathrm{O}+\mathrm{Li}_{2} \mathrm{CO}_{3} \leftrightarrow 2 \mathrm{LiHCO}_{3} \\
\mathrm{LiHCO}_{3} \leftrightarrow \mathrm{HCO}_{3}^{-}+\mathrm{Li}^{+} \\
\mathrm{HCO}_{3}^{-} \leftrightarrow \mathrm{CO}_{3}^{2-}+\mathrm{H}^{+} \\
\mathrm{HCO}_{3}^{2-}+\mathrm{H}^{+} \leftrightarrow \mathrm{H}_{2} \mathrm{O}+\mathrm{CO}_{2}
\end{aligned}
$$




$$
\mathrm{Li}_{2} \mathrm{CO}_{3} \leftrightarrow \mathrm{Li}^{+}+\mathrm{CO}_{3}{ }^{2-}
$$

Hereby, the possible recombinations between aqueous $\mathrm{CO}_{2}$-phases and lithium ions in aqueous phases are shown. These combinations can be transferred to other lithium phases, liberating lithium cations in aqueous solution, too:

If lithium is present as $\mathrm{LiF}$ is a black mass, it dissolves in aqueous media according to Equation (8) [59]:

$$
\mathrm{LiF}+\mathrm{H}_{2} \mathrm{O} \leftrightarrow \mathrm{HF}+\mathrm{LiOH}
$$

According to the definition of strong acids and bases [60], $\mathrm{HF}\left(\mathrm{pK}_{\mathrm{S}}=3.17\right.$ [61]) is a strong acid, whereas $\mathrm{LiOH}\left(\mathrm{pK}_{\mathrm{b}}=-0.36\right.$ [62]) is very strong base. As a resulting $\mathrm{pH}$-value for dissolving $0.26 \mathrm{~g} / \mathrm{L}$ at $25^{\circ} \mathrm{C} \mathrm{pH}=7-8.5$ is reported [63].

If lithium is formed as $\mathrm{LiOH}$ in a black mass, it dissociates in an aqueous solution according to Equation (9) [64-66]:

$$
\mathrm{LiOH}+\mathrm{H}_{2} \mathrm{O} \leftrightarrow \mathrm{Li}^{+}+\mathrm{OH}^{-}+\mathrm{H}_{2} \mathrm{O} \leftrightarrow \mathrm{LiOH} \cdot \mathrm{H}_{2} \mathrm{O}
$$

the following reaction can take place if $\mathrm{CO}_{2}$ is applied to the system [67]:

$$
2 \mathrm{LiOH} \cdot \mathrm{H}_{2} \mathrm{O}+\mathrm{CO}_{2} \leftrightarrow \mathrm{Li}_{2} \mathrm{CO}_{3}+3 \mathrm{H}_{2} \mathrm{O}
$$

If lithium is present as $\mathrm{Li}_{2} \mathrm{O}$ in a black mass, it dissociates to $\mathrm{LiOH}$ in aqueous solutions according to Equation (11) [68]. $\mathrm{LiOH}_{(\mathrm{aq})}$ is generally stable as lithium hydroxide octahydrate $\left(\mathrm{LiOH} \cdot 8 \mathrm{H}_{2} \mathrm{O}\right)[61]$.

$$
\mathrm{Li}_{2} \mathrm{O}+\mathrm{H}_{2} \mathrm{O} \leftrightarrow 2 \mathrm{LiOH}
$$

This passage has shown that no study on indirect carbonation by $\mathrm{CO}_{2}$ using whole LIBs black mass, meaning anode and cathode material, is in place. In contrast to that, in the study, real industrial heat-treated black mass from anode and cathode was used without adding a reducing agent. Moreover, this gives the first-time overview of all possible lithium reactions when considering battery materials, which is crucial to extract hypotheses on ongoing mechanisms.

\subsubsection{Solid-Gas Carbonation (Direct Thermal Carbonation)}

Direct carbonation describes solid-gas reactions for generating a carbonate phase [48]. In this study, it will be investigated by using $\mathrm{SCO}_{2}$. There are different studies in literature optimizing a reductive thermal treatment of black mass for mobilizing lithium via subsequent $\mathrm{H}_{2} \mathrm{O}$-leaching $[46,47,69-74]$. It should be recalled that in $[46,47]$, which were already discussed in chapter 1.1.3, a combination of direct carbonation and indirect carbonation was performed: On one hand, a reductive thermal treatment with adding a carbon-reducing agent like lignite or carbon black contributes to the formation of $\mathrm{Li}_{2} \mathrm{CO}_{3}$, hence direct carbonation. On the other hand, $\mathrm{CO}_{2}$ was added during leaching or $\mathrm{Na}_{2} \mathrm{CO}_{3}$ was used after a first filtration, both representing indirect carbonation. Therefore, a classification into studies with direct and indirect carbonation is not always straightforward.

However, in all reported studies [46,47,69-74], first, the battery cells are shredded, and, after extracting, a black mass is thermally treated. Battery systems used are LCO-cathode based [69,72,74], LMO-cathode based [71,74], or NMC-cathode based [73,74]. In [73], the only cathode material is used. Most studies focus on a thermal treatment in an inert atmosphere, like a vacuum, $\mathrm{Ar}$ or $\mathrm{N}_{2}[69,71,72,74,75]$ or in the air [70] instead of $\mathrm{CO}_{2} \cdot \mathrm{CO}_{2}$ was only used in [73]. The performed reductive roasting reportedly also contributes to the carbonation of lithium by precipitating it from the black mass matrix $[19,70,72,74,76]$.

Since the focus of this study is the use of NMC-cathode based black mass, the matching studies are reported in detail: $\mathrm{CO}_{2}$-gas purging at 600,700 and $800{ }^{\circ} \mathrm{C}$ (direct carbonation) of NMC-cathode material was performed by Wang et al. for $120 \mathrm{~min}$., but lithium yields are not given. Instead, it is stated that $1.735 \mathrm{~g}$ lithium of $1.95 \mathrm{~g}$ lithium was transferred to 
a solution after water leaching [73]. However, no optimal temperature for carbonation is given; instead, a spectrum of $650-800{ }^{\circ} \mathrm{C}$ is reported, and no discussion on lithium purity is in place. Xiao et al. treated black mass from NMC-cathode based cells. According to the best-case scenario for pyrolysis and $\mathrm{H}_{2} \mathrm{O}$-leaching, $66 \%$ of the lithium is recovered. The bestcase scenario here implies vacuum pyrolysis at $700{ }^{\circ} \mathrm{C}$ for $30 \mathrm{~min}$. in combination with $\mathrm{H}_{2} \mathrm{O}$ leaching for $30 \mathrm{~min}$. and an $\mathrm{s} / 1$ ratio of $1: 40(\mathrm{~g} / \mathrm{mL})(25 \mathrm{~g} / \mathrm{L})$ [74]. Nevertheless, no details on the procedure of NCM-black mass are given, especially regarding lithium recovery.

Since [73] is the only study in place using $\mathrm{CO}_{2}$ for direct carbonation, no detailed yields are quoted from the literature.

In terms of chemical reactions involving lithium phases, only a few data are given, mostly based on thermodynamic simulations [76-78]. Nonetheless, gas-solid reactions are known, e.g., from $\mathrm{CO}_{2}$ absorbing for air purification. Here, a reaction between $\mathrm{LiOH}$ and $\mathrm{CO}_{2}$ for generating lithium carbonate is targeted [67].

$$
2 \mathrm{LiOH}+\mathrm{CO}_{2} \rightarrow \mathrm{Li}_{2} \mathrm{CO}_{3}+\mathrm{H}_{2} \mathrm{O}
$$

A similar reaction is possible if $\mathrm{Li}_{2} \mathrm{O}$ is present [79]:

$$
\mathrm{Li}_{2} \mathrm{O}+\mathrm{CO}_{2} \rightarrow \mathrm{Li}_{2} \mathrm{CO}_{3}
$$

The reaction is rather a surface reaction, after which $\mathrm{CO}_{2}$ diffuses into the inner part of the $\mathrm{Li}_{2} \mathrm{O}$ particles. This diffusive process is temperature-supported. For example, at $600{ }^{\circ} \mathrm{C}$, the diffusion takes place 10 times faster than at $500{ }^{\circ} \mathrm{C}$ [79]. In addition, once lithium carbonate is formed, it remains stable in the $\mathrm{CO}_{2}$ atmosphere, even though being in a liquid state, until $1611^{\circ} \mathrm{C}$, before decomposing into $\mathrm{Li}_{2} \mathrm{O}$ [80]. This passage has shown that there is a lack of process details in terms of direct carbonation LIBs black mass by $\mathrm{CO}_{2}$-gas purging. Moreover, the available studies focus on shredding before thermal treatment. In this study, the thermal treatment is performed before a mechanical treatment.

Finally, at this point, no study has reported investigating the influence of solid/gas mechanisms (direct thermal carbonation) in contrast to liquid/gas mechanisms (indirect carbonation) in terms of carbonation either by using supercritical or ambient pressure $\mathrm{CO}_{2}$ and by keeping the process parameters equal. The present research aims to give answers to this question.

\subsubsection{The Role of Supercritical $\mathrm{CO}_{2}\left(\mathrm{SCCO}_{2}\right)$}

When using $\mathrm{CO}_{2}$ for phase transformations, the combination of the liquid and gaseous phase properties is advantageous. For $\mathrm{CO}_{2}$, the supercritical state is reached at a temperature of at least $31^{\circ} \mathrm{C}$ and a pressure of 73.8 bar [81]. Here, the physical properties of $\mathrm{CO}_{2}$ can be described by a density according to the liquid state and as viscosity equally to the gaseous state, enabling a high efficiency [82]. Chen et al. report on using supercritical $\mathrm{CO}_{2}\left(\mathrm{SCCO}_{2}\right)$ for carbonating spodumene-based lithium; thus, this study refers to primary lithium production [83]. In their study, also sodium carbonate $\left(\mathrm{Na}_{2} \mathrm{CO}_{3}\right)$ is used as a carbonation agent, and $\mathrm{CO}_{2}$ is added, aiming for a higher carbonate dissolution. It is reported to precipitate as $\mathrm{Li}_{2} \mathrm{CO}_{3}$ when reducing the liquid volume, according to Equation (14) [83]:

$$
2 \mathrm{LiHCO}_{3(\mathrm{aq})} \leftrightarrow \mathrm{Li}_{2} \mathrm{CO}_{3(\mathrm{~s})}+\left\{\mathrm{CO}_{2}\right\}+\mathrm{H}_{2} \mathrm{O}_{(\mathrm{aq})}
$$

Bertau et al. have dealt with a similar research topic: They suggested a treatment of Zinnwaldite, a lithium ore located in Germany, with $\mathrm{SCCO}_{2}$. It is a promising solution for primary lithium recovery as carbonate [84]. Specific benefits comprise the avoidance of additional chemicals, such as $\mathrm{Na}_{2} \mathrm{CO}_{3}$, and significant lithium losses, the economic viability due to the low $\mathrm{CO}_{2}$ price, and the high selectivity by transforming only alkali metal compounds [84]. Moreover, Liu et al. investigated the possibilities of recovering LIB-electrolyte components by means of $\mathrm{SCCO}_{2}$ [85]. Grützke et al. also aimed for LIB-electrolyte recycling using $\mathrm{SCCO}_{2}$, but in contrast to Liu et al., who used synthetic 
electrolyte components, whole end-of-life NMC-cells were discharged, deep-frozen and manually opened to extract the electrolyte by supercritical $\mathrm{CO}_{2}[86,87] . \mathrm{SCCO}_{2}$, at, e.g., $40{ }^{\circ} \mathrm{C}$ and 80 bar in flow-through mode, is used for extracting the electrolyte along with the $\mathrm{CO}_{2}$-stream in a cryogenic trap. A patented technique by Sloop describes a treatment of full batteries with $\mathrm{SCCO}_{2}$, where lithium carbonate from the electrolyte is recovered in the frame of electrolyte removal. The electrolyte removal is reached by dissolving it in the stream of $\mathrm{CO}_{2}[81,88]$.

Rothermel et al. rather focused on graphite recycling options and the achievable graphite purity by making use of supercritical $\mathrm{CO}_{2}$-supported electrolyte recovery $\left(\mathrm{SCCO}_{2}\right)$ [89]. In 2019, Bertau et al. also reported options to recover lithium from battery black mass [90]. The so-called COOL process, consisting of discharging, mechanical extraction of black mass and a $\mathrm{SCCO}_{2}$ treatment, obtained lithium carbonate with a purity of $>99.5 \%$ and yield of $60 \%$, but the yield is referring to primary ore treatments, so no information on lithium from black mass is in place [90]. In this context, another benefit is highlighted: consuming $\mathrm{CO}_{2}$ instead of producing $\mathrm{CO}_{2}$ in the context of rising industrial, environmentally harmful $\mathrm{CO}_{2}$-emissions [90]. However, no details about the best-case treatment parameters and the resulting lithium yields in terms of black mass carbonation are given. An earlier patent by Bertau et al. describes lithium recovery from so-called lithium-containing battery residues by $\mathrm{SCCO}_{2}$ for obtaining lithium carbonate [91]. For this material, lithium yields of $>90 \%$ are reported by using electrodialysis and subsequent addition of carbonates like $\mathrm{Na}_{2} \mathrm{CO}_{3}$ or $\mathrm{K}_{2} \mathrm{CO}_{3}$, but facts on the corresponding treatment details and parameters are not given. An exemplary process with $\mathrm{s} / 1=1: 40(\mathrm{~g} / \mathrm{mL})(50 \mathrm{~g} / 2 \mathrm{~L}), 4 \mathrm{~h}$ at $230^{\circ} \mathrm{C}$ and $100 \mathrm{bar}$ is described, reporting on a leaching efficiency of $95 \%$. The lithium extraction via electrodialysis takes place in a $\mathrm{Li}_{2} \mathrm{SO}_{4}$-solution recovering $98 \%$ of the lithium in solution [91]. A lithium yield based on the final, solid product is not given.

This passage has shown that supercritical $\mathrm{CO}_{2}$ plays a role in lithium recovery from different materials, but for LIB-black mass, there is a lack of knowledge regarding decisive process details. This article focuses on lithium carbonation from black mass by means of supercritical $\mathrm{CO}_{2}$.

\section{Materials and Methods}

\subsection{Recycling Concept with Integrated Early-Stage Li-Recovery}

Under the view of the current process-related drawbacks in conventional recycling processes, and especially in terms of the need for lithium recovery, this study suggests the strategy of an early-stage Li-recovery ("ESLR") process. The method "early-stage" is studied here, describing lithium carbonation before entering acidic leaching or smelting, hence at an earlier position in the recycling chain. This treatment prevents lithium distribution, the further use of additives needed for hydrometallurgical treatments, and costly refining from a slag. The "ESLR" process comprises the following steps, as presented in Figure 5b: After the cells have been deactivated by means of a thermal treatment followed by mechanical processing (shredding and sieving to $<1 \mathrm{~mm}$ ), lithium is enriched in the heat-treated black mass, along with other electrode elements, such as $\mathrm{Co}, \mathrm{Ni}, \mathrm{Mn}$, and $\mathrm{C}$ and partly Al- and $\mathrm{Cu}$ foil fragments. This heat-treated black mass is then leached in $\mathrm{H}_{2} \mathrm{O}$ - to transform and extract the lithium phases and, thus, separated them from the other electrode elements. 


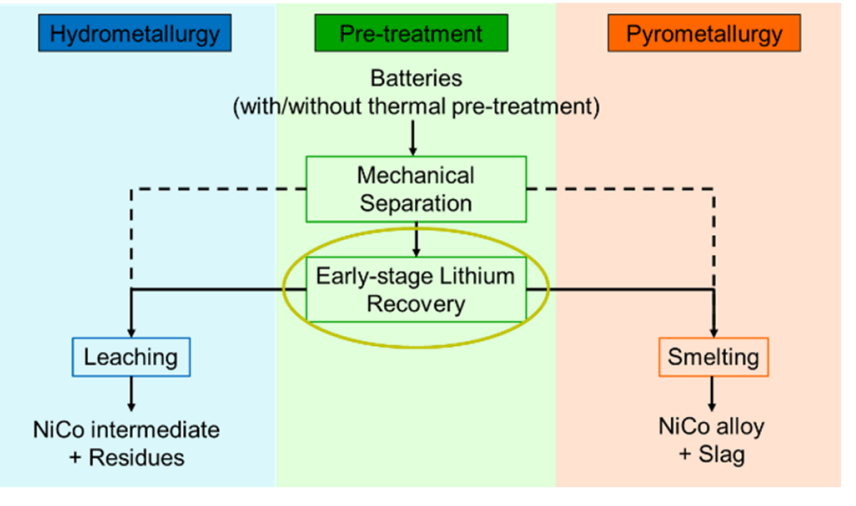

(a)

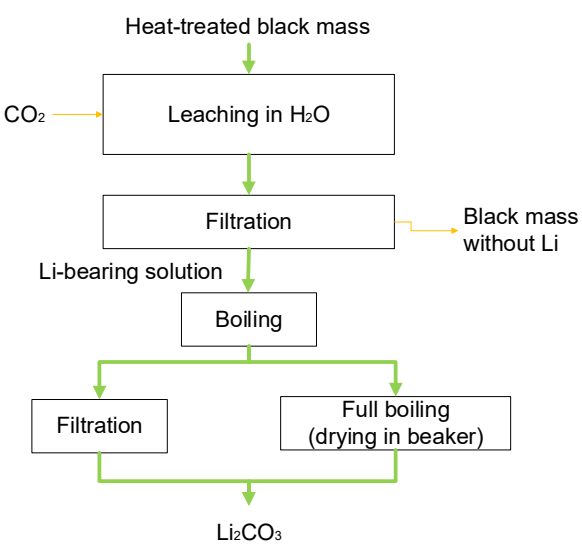

(b)

Figure 5. (a) Recycling strategy for lithium-ion batteries (LIBs) at IME with a focus on alternative processing using "ESLR", (b) detailed process steps of the "ESLR" process by autoclave/supercritical $\mathrm{CO}_{2}$-carbonation.

As mentioned in Section 1, this phase transformation can be realized by treatment with supercritical $\mathrm{CO}_{2}$ as indirect or direct carbonation. Lithium in the heat-treated black mass is converted into water-soluble lithium hydrogen carbonate $\left(\mathrm{LiHCO}_{3}\right)$ and lithium carbonate $\left(\mathrm{Li}_{2} \mathrm{CO}_{3}\right)$. Indirect carbonation and $\mathrm{H}_{2} \mathrm{O}$-leaching occur simultaneously because the heat-treated black mass is fed in the reactor along with deionized water. In direct carbonation, the heat-treated black mass is subjected to neutral leaching in deionized $\mathrm{H}_{2} \mathrm{O}$ after the phase transformation of lithium compounds. In both cases, lithium dissolves into an aqueous solution, and the Li-reduced, heat-treated black mass is separated by a first filtration. The first filtration's products comprise:

1. A filter cake with mainly carbon, nickel, cobalt, manganese, aluminum and copper fragments and a share of lithium ( $\rightarrow$ C-filter cake);

2. A lithium-bearing filtrate (solution)

The Li-containing filtrate must finally be boiled since lithium's solubility decreases from $13.3 \mathrm{~g} / \mathrm{L}$ at $20^{\circ} \mathrm{C}$ to $7.2 \mathrm{~g} / \mathrm{L}$ by heating to $100{ }^{\circ} \mathrm{C}$ [25]. Moreover, thus, the carbonate precipitation is supported. Either a second filtration step separates the solid carbonate (filter cake) from the residual solution, or the solution is further boiled and is left in the air to dry the carbonate.

\subsection{Material Characterization}

The black mass used in the present study to validate the "ESLR" process has been generated by thermal treatment of whole NCM-traction cells. Therefore, a real industrial heat-treated black mass was obtained by thermal treatment at different atmospheres: Ar, $95 \% \mathrm{Ar}+5 \% \mathrm{O}_{2}$ and $\mathrm{CO}_{2}$. For Ar-pyrolysis, the temperatures targeted are $509{ }^{\circ} \mathrm{C}$ and $603{ }^{\circ} \mathrm{C}$. For $\mathrm{Ar}+\mathrm{O}_{2}$-pyrolysis, the temperature targeted is $501{ }^{\circ} \mathrm{C}$. For $\mathrm{CO}_{2}$-pyrolysis, the targeted temperature is $466^{\circ} \mathrm{C}$. These atmospheres have been generated by dynamic pyrolysis in a sealed reactor. It should be noted that due to the experimental setup, not all thermal treatment temperatures have been identical. The thermally treated cells were then subjected to a shredding and sieving process for extracting the heat-treated black mass. The composition of the heat-treated black mass is shown below (see Table 2):

Table 2. Chemical composition of the heat-treated black mass used for the autoclave trials pyrolyzed in Ar-atmosphere.

\begin{tabular}{cccccccccc}
\hline Al & Co & Cu & F & Fe & Li & Mn & P & C & Ni \\
\hline \multicolumn{8}{c}{. } & \multicolumn{8}{c}{ wt. $\%$} \\
\hline 2.10 & 11.7 & 0.88 & 4.10 & 0.00 & 3.69 & 8.91 & 0.44 & 33.9 & 11.5 \\
\hline
\end{tabular}


Dynamic particle analysis with QICPIC/L02 (Sympatec GmbH, Clausthal-Zellerfeld, Germany) of the heat-treated black mass reveals that according to the distribution sum $\left(\mathrm{Q}_{3}\right)$, the $\mathrm{d}_{99.3}$-value is $101.74 \mu \mathrm{m}$. This means that $99.3 \%$ of the heat-treated black mass has a grain size smaller than $101.74 \mu \mathrm{m}$ (see Figure 6). Here, the material's distribution density $\left(\mathrm{q}_{3}^{*}\right)$, see Equation (15), can also be extracted, reaching a global maximum at $\sim 95 \mu \mathrm{m}$. According to DIN ISO 9276-1, the distribution density is defined as the first derivation of the distribution sum:

$$
\mathrm{q}_{3} *=\mathrm{qr}(x)=\frac{\mathrm{dQ}_{\mathrm{r}}(x)}{\mathrm{d} x}
$$

Furthermore, the distribution sum of the particles represents the number of all particles and not their volume share in the powder. Hence, there are many small particles in the heat-treated black mass, but in contrast to that, the volume of big particles $(>101.74 \mu \mathrm{m})$ could take up more than $99.3 \%$. Moreover, the largest particle detected in the heat-treated black mass comprises a diameter (EQPC) of $653.74 \mu \mathrm{m}$ with a FERET_MAX value of even $748.13 \mu \mathrm{m}$. EQPC is defined as

$$
x \mathrm{EQPC}=\sqrt[2]{\frac{\mathrm{A}}{\pi}}
$$

Hence, it describes the diameter of a circle whose projection surface (shadow) is identical to the particle. FERET_MAX, on the other hand, detects the maximum diameter of a particle by analyzing it from 20 different perspectives between 0 and $180^{\circ}$. This value deviates from the EQPC, especially in terms of irregularly shaped particles; hence, FERET_MAX takes bigger values, especially when being distinct from a circular form. The maximum detectable particle size with this method comprises $1252 \mu \mathrm{m}$.

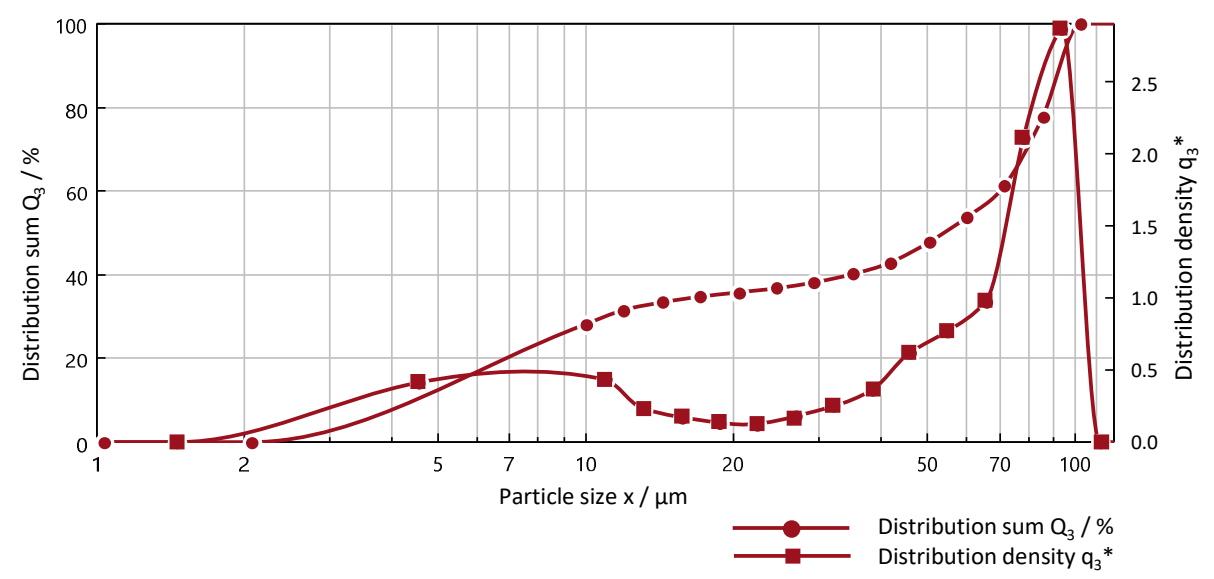

Figure 6. Dynamic particle analysis of $\mathrm{CO}_{2}$-pyrolyzed black mass. A total of 32,650 particles were counted and hence considered for the evaluation. The distribution sum and distribution density in this diagram is based on the heat-treated black mass comprises a diameter (EQPC)-value of the particles, which is indicated as particle size $x$.

More details on the quantitative grain size detected are shown in Figure 7 and can be extracted from the chemical composition of the particles. EDS analyses were carried out for elemental mapping, as well as for point analysis on the black powder, using a ZeissGemini-FE-SEM, equipped with an Oxford UltimMax170 detector (Carl Zeiss AG, Oberkochen, Germany). In Figure 7a,b, the results of the elemental mapping (EDX-layered image) are depicted. Here, the appearance of metallic Al-flakes is shown in Figure 7a; second, a heat-treated black mass particle and a graphite particle are shown in Figure $7 \mathrm{~b}$. Moreover, third, Figure $7 \mathrm{c}$ is a $1 \mathrm{~mm}$-scale distance shot showing the heterogeneity of the heat-treated black mass in terms of metallic aluminum fragments, heat-treated black mass particles and graphite powder. It should be noted that lithium cannot be displayed by this method. In addition, Figure $7 c$ reveals that the liberation of heat-treated black mass from 
the aluminum current collectors could be realized since the particles do not show direct physical contact.

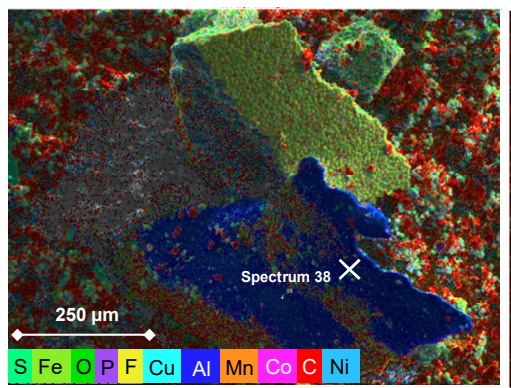

(a)

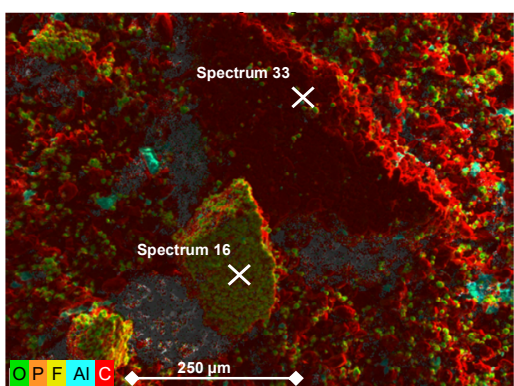

(b)

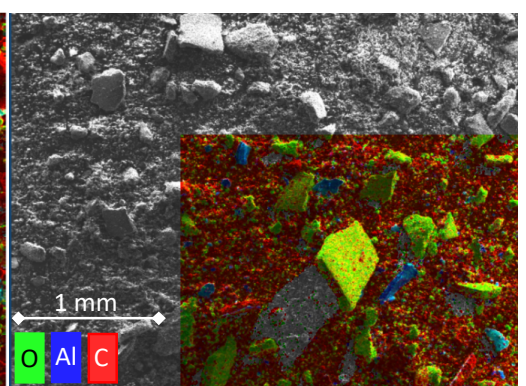

(c)

Figure 7. EDS analysis of $\mathrm{CO}_{2}$-pyrolyzed EV-battery black mass. (a) results of the elemental mapping (EDX-layered image) of an aluminum particle, (b) results of the elemental mapping (EDX-layered image) of both an NMC-and-graphite particle, (c) Distance shot of the heat-treated black mass from elemental mapping (EDX-layered image).

The following Table 3 shows the chemical composition of the taken spectra. Here, the chemical composition of the Al-flake can be seen by Spectrum 38. However, there are some oxide-graphite-mix particles visible, which results in the chemical composition of just 58.28 wt. \%. Moreover, spectrum 16 shows that the dominant particle composition is a Ni-Mn-Co-Oxide, hence, heat-treated black mass particles. Spectrum 33 reflects a graphite particle $(C=46.46 \mathrm{wt} . \%)$, which also shows a high amount of oxygen. This may be explained by lithium oxides, hydroxides or carbonates, which cannot be shown here. This theory can be supported by the lithium intercalation in the graphite matrix due to charging.

Table 3. Chemical composition of the heat-treated black mass spectra taken by EDS-analysis. Only elements $>1 \mathrm{wt} . \%$ are shown quantitatively.

\begin{tabular}{ccccccccc}
\hline Element & $\mathbf{C}$ & $\mathbf{O}$ & $\mathbf{F}$ & $\mathbf{P}$ & $\mathbf{M n}$ & $\mathbf{C o}$ & $\mathbf{N i}$ & $\mathbf{A l}$ \\
\hline Unit & & \multicolumn{7}{c}{ wt. $\%$} \\
\hline Spectrum 38 & 31.9 & 7.35 & $<1$ wt. $\%$ & $<1$ wt. $\%$ & $<1$ wt. $\%$ & $<1$ wt. $\%$ & $<1$ wt. $\%$ & 58.28 \\
\hline Spectrum 16 & 32.83 & 12.1 & 21.9 & 1.81 & 8.59 & 11.38 & 10.62 & $<1$ wt. $\%$ \\
\hline Spectrum 33 & 46.46 & 33.51 & 1.47 & $<1$ wt. $\%$ & $<1$ wt. $\%$ & $<1$ wt. $\%$ & $<1$ wt. $\%$ & 17.95 \\
\hline
\end{tabular}

These findings are essential to understand the properties of NCM-heat-treated black mass: An important result is the revelation of the material's heterogeneity. Hence, each sample taken shows different chemical compositions. Considering the colorful mixture of relatively big Al-particles, cathode material particles and smaller graphite/soot particles, this statement is supported. Moreover, it can be seen that the Al-foils are liberated from the cathode material. Hence, a thermal pretreatment removes binders and therefore loosens adhesions. This enhances the subsequent leaching efficiency, as indicated before. Moreover, it is shown that fluorine enriches the cathode material particles.

\subsection{Neutral Leaching Reference Tests in Deionized $\mathrm{H}_{2} \mathrm{O}$}

Neutral leaching comprises reference trials to evaluate the carbonation success. It was performed in a $1 \mathrm{~L}$ glassware beaker filled with deionized water. Here, $20 \mathrm{~g}$ of the heat-treated black mass is inserted and magnetically stirred at $350 \mathrm{rpm}$ for the defined leaching time. After $\mathrm{H}_{2} \mathrm{O}$-leaching, a first filtration obtains a C-filter cake and a Li-bearing solution, then boiled to recover lithium as $\mathrm{L}_{\mathrm{i} 2} \mathrm{CO}_{3}$ ( $\rightarrow \mathrm{Li}$-filter cake). Neutral leaching is performed at room temperature to increase lithium dissolution. Lithium contents in both filter cakes and solutions are measured by ICP-OES (inductively coupled plasma optical 
emission spectrometry). Li is the crucial indicator for carbonation success, and hence, lithium yields are calculated as follows:

$$
n_{\mathrm{Li}}=\frac{\mathrm{Li}_{\mathrm{Li}_{2} \mathrm{CO}_{3}-\mathrm{fc}}(\mathrm{g})}{\mathrm{Li}_{\text {total }}(\mathrm{g})}
$$

where $\mathrm{Li}_{\text {total }}$ is the lithium mass in the input, and $\mathrm{Li}_{-} \mathrm{Li}_{2} \mathrm{CO}-\mathrm{fc}$ is the lithium mass in the lithium carbonate filter cake. Since the input material shows deviations in terms of its chemical composition, the $\mathrm{Li}_{\text {total }}$ value does not equal the share of the original input analysis. For this reason, the lithium values in the input are calculated as follows:

$$
\mathrm{Li}_{\text {total }}(\mathrm{g})=\mathrm{Li}_{\mathrm{C}-\mathrm{fc}}(\mathrm{g})+\mathrm{Li}_{\text {solution }}(\mathrm{g})
$$

Here, C-fc represents the carbon filter cake, also indicated as "heat-treated black mass without lithium," and "Li $\mathrm{s}_{\text {solution" }}$ " corresponds to "Li-bearing solution". This calculation is to be contrasted to the leaching efficiency (LE). When calculating $n_{\mathrm{Li}}$ based on $\mathrm{Li}_{\text {solution }}$ [g], the yields in this study were $\sim 10 \%$ higher. For example, in one trial with a yield of $79 \%$ based on Equation (17), the LE was $88 \%$. The reason for this inaccuracy cannot be determined at this point, but since the deviation was systematic, the authors decided to use the lower values for conservative result interpretation.

\subsection{Carbonation by Supercritical $\mathrm{CO}_{2}$}

The unit operation used is a batch 11 Büchi autoclave reactor operated with deionized water (indirect carbonation) or without any liquid (direct carbonation). The maximum operating temperature is $250{ }^{\circ} \mathrm{C}$, and the maximum applicable pressure is $200 \mathrm{bar}$. After sealing, a stirrer constantly mixes the powder (50 g heat-treated black mass per trial (T0-T9) and $20 \mathrm{~g}$ heat-treated black mass per trial (T10-T22) or the suspension in the reactor. The gas flows into the reactor occurs via a valve into $\mathrm{H}_{2} \mathrm{O}$ if the trial is conducted with an aqueous medium. As soon as the supercritical conditions are reached, a processing time of $120 \mathrm{~min}$ is started. The defined holding time of $120 \mathrm{~min}$ can be attributed to preliminary studies using autoclave-induced carbonation [92]. The general parameters for the autoclave trials can be seen in Figure 8a. Moreover, Figure 8b shows pictures of the unit operation.

\begin{tabular}{c|c} 
Pressurestart & $50 \mathrm{bar}$ \\
\hline Heating rate & $10{ }^{\circ} \mathrm{C} / \mathrm{min}$. \\
\hline Tmax & $230^{\circ} \mathrm{C}$ \\
\hline $\begin{array}{c}\mathbf{P}_{\max } \text { (spectrum of } \\
\text { trials) }\end{array}$ & $95.4-138.3 \mathrm{bar}$ \\
\hline Holding time & $120 \mathrm{~min}$. \\
\hline
\end{tabular}

(a)
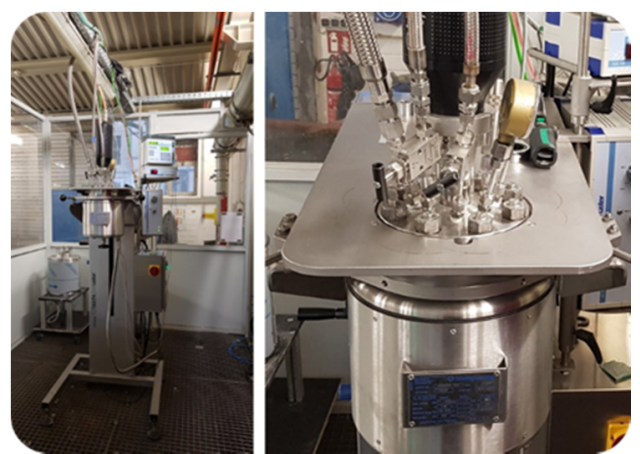

(b)

Figure 8. (a). Fixed process parameters and reached pressures for an autoclave trial (combination of heat-treated black mass with deionized $\mathrm{H}_{2} \mathrm{O}$ and $\mathrm{CO}_{2}$ gas) in case of trials T1-T9. After the starting pressure of 50 bar, the reactor is heated until reaching $230{ }^{\circ} \mathrm{C}$, resulting in different $P_{\max }$. (b): Used autoclave reactor at IME, RWTH Aachen University.

After leaching, either during autoclave treatment, if $\mathrm{H}_{2} \mathrm{O}$ is used in the autoclave or after the autoclave, if no $\mathrm{H}_{2} \mathrm{O}$ is used in the autoclave, a first filtration is performed. The experimental procedure is identical to the procedure described in Section 2.3: Boiling is performed to reduce the volume of liquid and to precipitate Li from the solution. Lithium is obtained in the form of solid $\mathrm{Li}_{2} \mathrm{CO}_{3}$ in a subsequent (second) filtration step or by full boiling until obtaining a solid $\mathrm{Li}_{2} \mathrm{CO}_{3}$ product within the beaker. The (second) filtration 
step is performed as follows: The Li-bearing solution is boiled until reaching $100 \mathrm{~mL}$ and then is filtrated, obtaining $\mathrm{Li}_{2} \mathrm{CO}_{3}$. The $\mathrm{Li}_{2} \mathrm{CO}_{3}$-filter cake is then washed with pure ethanol since lithium carbonate does not show solubility in ethanol. It is dried for at least $24 \mathrm{~h}$ and then weighed. The full boiling (indicated as "drying in a beaker") is performed as follows: The Li-bearing solution is boiled until no liquid is left, why the weight of the empty beaker is to be measured before and after performing full boiling. In addition, weighing is done after a drying time of at least $24 \mathrm{~h}$, too. The difference in weight equals the solid carbonate obtained.

An overview of the experimental series described in Sections 2.3 and 2.4 is given in Table 4. Parameter set 1.A, 1.O and 1.C (reference trials) represents $\mathrm{H}_{2} \mathrm{O}$-leaching without $\mathrm{CO}_{2}$ addition. Hereby, insights into the mass of water-soluble Li-phases already present in the heat-treated black mass are provided. Enhanced leaching efficiencies are obtained by combining neutral leaching with $\mathrm{CO}_{2}$-carbonation. (see experimental series 2.A, 2.O and 2.C). Moreover, carbonation trials were conducted in the autoclave as well by using argon (Ar) as process gas aiming for the same excess pressures as needed for the supercritical state (73.8 bar) (see Table 4, Parameter set 3.A). Ar as inert gas can deliver knowledge on the main mechanism for ongoing phase transformations: Either the presence of $\mathrm{CO}_{2}$ or the extreme pressure. Parameter set 4.A detects the influence of an autoclave setup without $\mathrm{H}_{2} \mathrm{O}$ and with $\mathrm{CO}_{2}$ to find out whether gas-solid or gas-liquid reactions dominate in carbonation.

Table 4. Parameter matrix for combining pyrolysis conditions with autoclave conditions in this study. Reference trials represent $\mathrm{H}_{2} \mathrm{O}$-leaching without autoclave or $\mathrm{CO}_{2}$-incorporation.

\begin{tabular}{|c|c|c|c|c|}
\hline & & \multicolumn{3}{|c|}{ Pyrolysis Conditions } \\
\hline & & $\begin{array}{c}\text { Ar- } \\
\text { Atmosphere }\end{array}$ & $\begin{array}{c}95 \% \text { Ar }+5 \% \\
\mathrm{O}_{2} \text {-Atmosphere }\end{array}$ & $\begin{array}{c}\mathrm{CO}_{2-} \\
\text { Atmosphere }\end{array}$ \\
\hline \multirow{4}{*}{$\begin{array}{l}\text { Autoclave } \\
\text { conditions }\end{array}$} & $\begin{array}{l}\mathrm{H}_{2} \mathrm{O} \text {-leaching } \\
\text { (reference trials) }\end{array}$ & 1.A & $1 . \mathrm{O}$ & 1.C \\
\hline & $\mathrm{SCCO}_{2}+\mathrm{H}_{2} \mathrm{O}$ & 2.A & $2 . \mathrm{O}$ & 2.C \\
\hline & $\mathrm{Ar}+\mathrm{H}_{2} \mathrm{O}$ & 3.A & $\mathrm{n} / \mathrm{a}$ & $\mathrm{n} / \mathrm{a}$ \\
\hline & $\mathrm{CO}_{2}+$ dry autoclave & 4.A & $\mathrm{n} / \mathrm{a}$ & $\mathrm{n} / \mathrm{a}$ \\
\hline
\end{tabular}

The labels of the trials are to be understood as follows: "number.letter", where the number stands for an experimental series: $1=$ neutral leaching in $\mathrm{H}_{2} \mathrm{O}$ without an autoclave, 2 = autoclave operated with $\mathrm{SCCO}_{2}+\mathrm{H}_{2} \mathrm{O}, 3=$ autoclave operated with $\mathrm{Ar}+\mathrm{H}_{2} \mathrm{O}$, $4=$ autoclave operated with $\mathrm{SCCO}_{2}$ and without $\mathrm{H}_{2} \mathrm{O}$. The letter stands for the pyrolysis atmosphere: $\mathrm{A}=$ Ar-pyrolysis, $\mathrm{O}=95 \mathrm{vol} \% \mathrm{Ar}+5 \mathrm{vol} \% \mathrm{O}_{2}$-pyrolysis, $\mathrm{C}=\mathrm{CO}_{2}$-pyrolysis. In this study, only experimental series 1 and 2 take different pyrolysis atmospheres into account. Hence, the fields of experimental series 3.O/3.C and 4.O/4.C are not experimentally conducted yet $(\mathrm{n} / \mathrm{a})$.

\section{Results}

In this Section, the results of the trial series 1.A-4.A, 1.O/2.O and 1.C/2.C are discussed by lithium yields. Moreover, Sankey diagrams of the lithium distribution and bar charts on the impurities of the lithium filter cake are shown for trials 1.A.1 and T2 (2.A). The evaluation calculations are performed, as described in Section 2.3.

\subsection{Neutral Leaching in Deionized $\mathrm{H}_{2} \mathrm{O}$}

For a profound understanding of water-soluble lithium phases already present in the heat-treated black mass, the following results can be obtained. In total, 40 experiments were conducted in experimental series 1.A, 1.O, and 1.C. The amount per parameter set comprises one trial, except for trials 1.A.2-1.A.4, 1.A.5-1.A.7, 1.A.28 and 1.A.40. Since the results are in good accordance, the other trials have not been repeated. All trials have in 
common that when charging heat-treated black mass in $\mathrm{H}_{2} \mathrm{O}$, the $\mathrm{pH}$ value of the solution has become alkaline $(\mathrm{pH}=11-12)$.

Figure 9 accordingly reveals how lithium yields from leaching heat-treated black mass in $\mathrm{H}_{2} \mathrm{O}$ (neutral leaching) depend on six main parameters:

1. Washing of C-filter cake with deionized water: if this parameter is performed, it is important to keep the washing volume constant. In this study, $200 \mathrm{~mL}$ of deionized water are used;

2. Filtration of Li-filter cake or full boiling: full boiling describes the removal of $\mathrm{H}_{2} \mathrm{O}$ in the laboratory beaker. Filtration stands for filtering the precipitating $\mathrm{Li}_{2} \mathrm{CO}_{3}$ at a minimum liquid volume. Hence, there are losses in the residual filtrate. Filtration is conventionally used after acidic leaching to avoid a co-precipitation of acid components and chemical additives;

3. Leaching time: 5, 30, 90 and $120 \mathrm{~min}$;

4. Particle size of heat-treated black mass: $<1 \mathrm{~mm}$ vs. $<90 \mu \mathrm{m}$. The particles $<90 \mu \mathrm{m}$ are obtained by additional grinding of the heat-treated black mass;

5. Solid/liquid ratio $(\mathrm{g} / \mathrm{mL}): 1: 10,1: 15,1: 22.5$ and 1:30;

6. Pyrolysis temperature: 501 vs. $603^{\circ} \mathrm{C}$ in Ar-pyrolysis

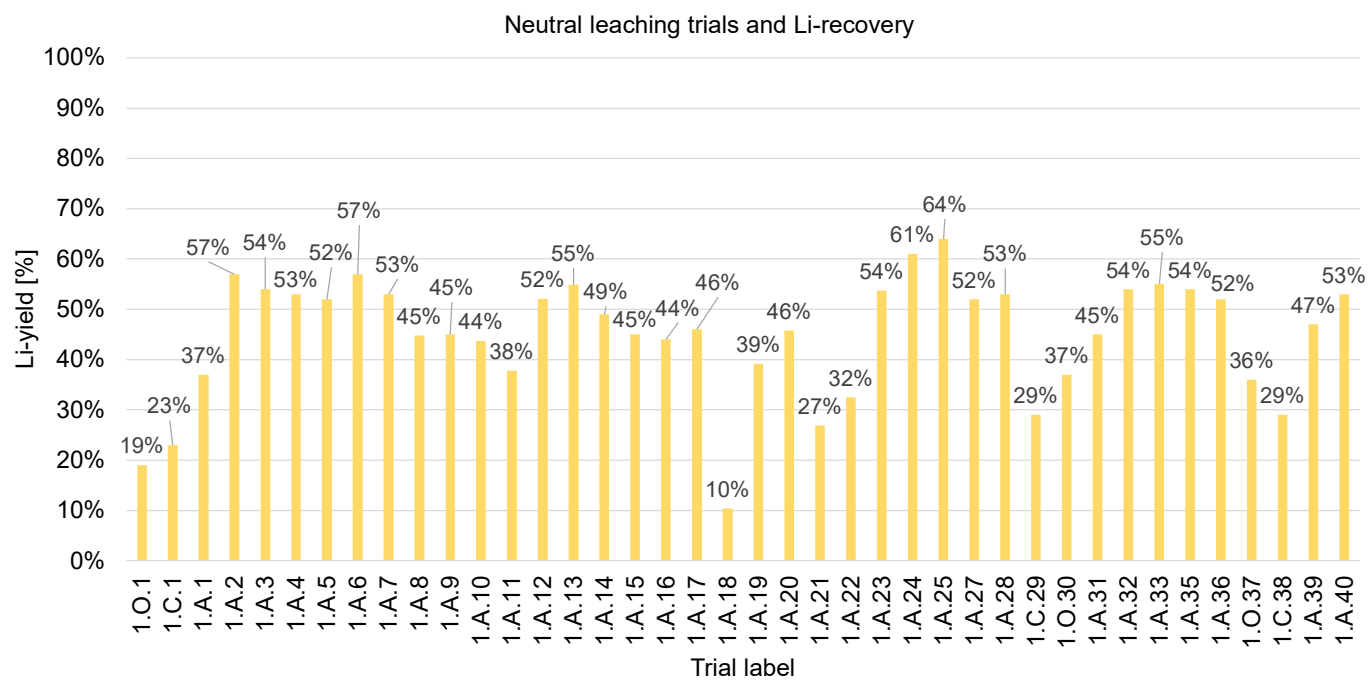

Figure 9. Lithium yields when applying no carbonation (neutral leaching) dependent on the parameters used. Trials $1 . A .26$ and 1.A.34 are left out of this overview since they comprise kinetic trials, for which a yield calculation is not possible due to heat-treated black mass losses during sampling.

Here, a variation of the selected parameters has an impact on the lithium yield. To evaluate the key influencing factors, representative trials are extracted and shown in detail. For efficiency reasons, only the results of experimental series 1.A are depicted for the evaluation according to the parameters selected. In terms of these influencing factors, the following conclusions are possible:

\section{Washing of C-filter cake with deionized water:}

The detailed observation of trials whose parameter combination was equal apart from the washing of the C-filter cake shows that washing is highly beneficial. During the filtration of the C-filter cake, there are physical depositions of the Li-bearing solution left in the C-filter cake. Hence, washing with deionized water liberates the C-filter cake from remaining lithium ions (see Figure 10a). 


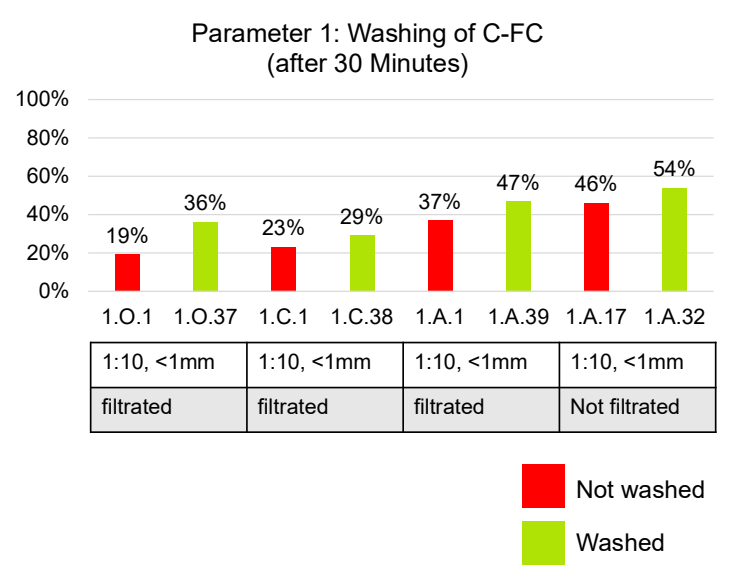

(a)

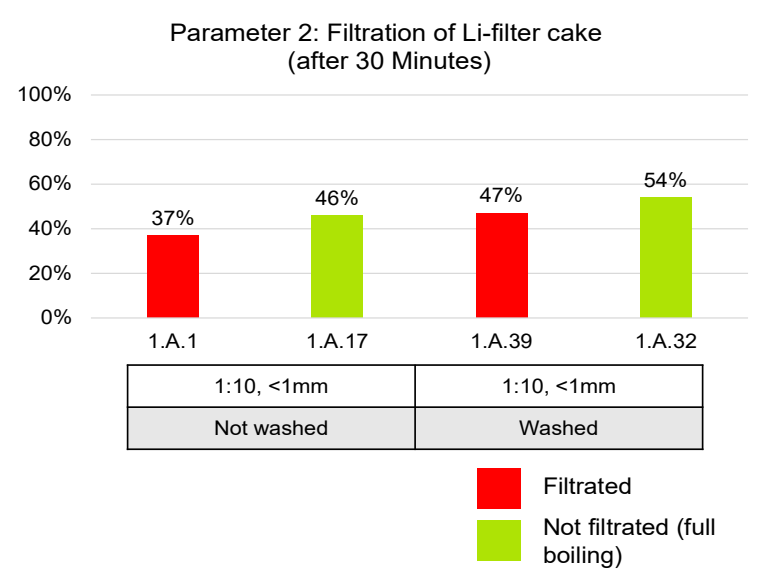

(b)

Figure 10. Detailed observation on achievable lithium yields by neutral leaching $\left(\mathrm{H}_{2} \mathrm{O}\right)$ of heat-treated black mass. (a) Parameter 1: washing of C-filter cake. (b) Parameter 2: filtration of Li-filter cake or full boiling.

\section{Filtration of Li-filter cake or full boiling:}

Filtration is, according to Figure 10b, not an adequate tool when applying neutral leaching in $\mathrm{H}_{2} \mathrm{O}$. However, this analysis only focuses on lithium distribution. Hence, no information on filter cake impurities, e.g., $\mathrm{F}$ is given here.

\section{Leaching time:}

The optimal leaching time cannot be extracted from the performed trials, as can be seen in the range between 5 and $90 \mathrm{~min}$ (see Figure 11a) and between 30 and $120 \mathrm{~min}$ (see Figure 11b). Here, no significant improvement of dissolved lithium is achieved when comparing trials with constant parameters except for the leaching time.

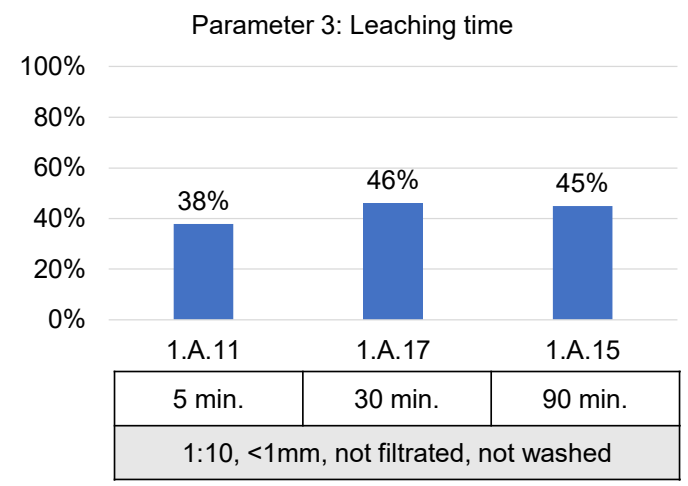

(a)

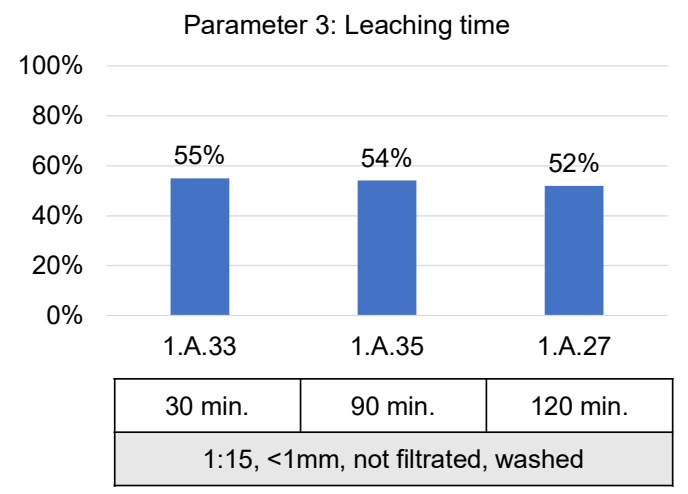

(b)

Figure 11. Detailed observation on achievable lithium yields by neutral leaching $\left(\mathrm{H}_{2} \mathrm{O}\right)$ of black mass. The considered parameter is parameter 3: leaching time. (a) Dissolution and lithium recovery by comparing trials with a leaching time between 5 and $90 \mathrm{~min}$. (b) Dissolution and lithium recovery by comparing trials with a leaching time between 30 and $120 \mathrm{~min}$.

Reduced lithium shares over time can be explained by slight deviations in the chemical composition. Hence, deviations in lithium yields are also possible, also due to different lithium phases in the heat-treated black mass. Therefore, a kinetic trial can be found in Figure 12. It can be seen that lithium compounds in the heat-treated black mass of the Ar-pyrolyzed battery cells dissolve as ions instantly. Although the lithium yield can be found below Figure 12, it cannot be directly transferred to the other neutral leaching trials since the amount of heat-treated black mass, and therefore the lithium-bearing input is reduced each time a sample is taken. Samples were taken from the leaching liquor by 
using a particle filter, why redirecting the lost particles to the liquid was not possible. In an upscale setup, this mass reduction would show a lower impact. The calculation of lithium yields is based on a reduced leaching liquor volume by sample extraction. The last sample is taken, at $125 \mathrm{~min}$, shows increased lithium mass, which can be explained by analytical deviations.

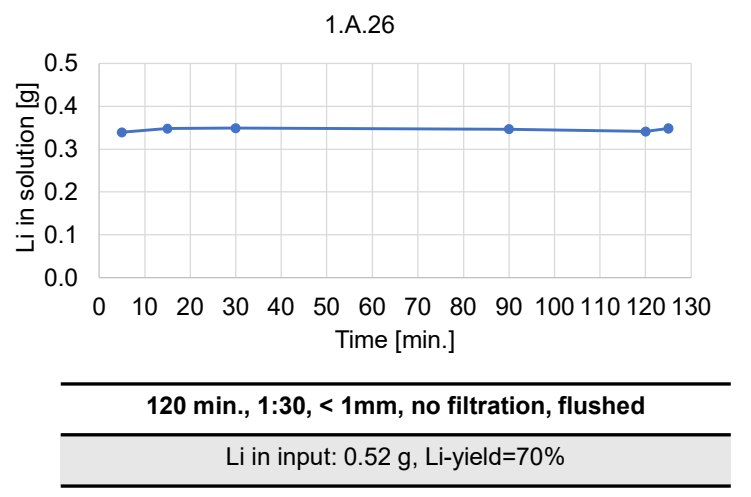

Figure 12. Kinetic trial for lithium dissolution in deionized $\mathrm{H}_{2} \mathrm{O}$ at an $\mathrm{s} / 1$ ratio of 1:30.

\section{Particle size of heat-treated black mass:}

As already reported, $99.3 \%$ of black mass particles have a grain size below $101.74 \mu \mathrm{m}$. In order to reduce the grain size of the few particles above this threshold, the heat-treated black mass was ground in a planetary mill. The aim of this approach was to detect the correlation between smaller grain size and an eased liberation of lithium compounds in neutral leaching. In Figure 13a, no difference with or without grinding is detected. In Figure 13b, this trend shows slightly irregular behavior when comparing trial 1.A.19 to trial 1.A.20. However, in no parameter combination and hence, trial pair compared, grinding to $<90 \mu \mathrm{m}$ has shown an improved lithium yield. This can be explained by the grain size distribution shown before: The majority of the particles shows grain sizes below $100 \mu \mathrm{m}$.

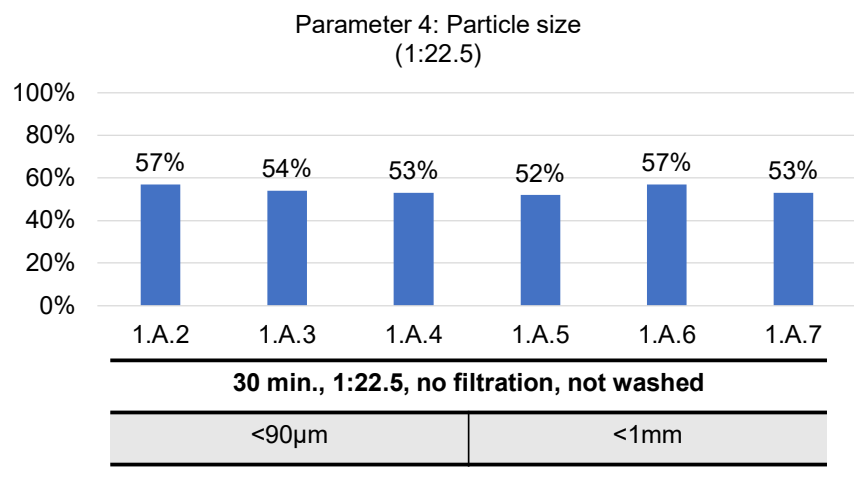

(a)

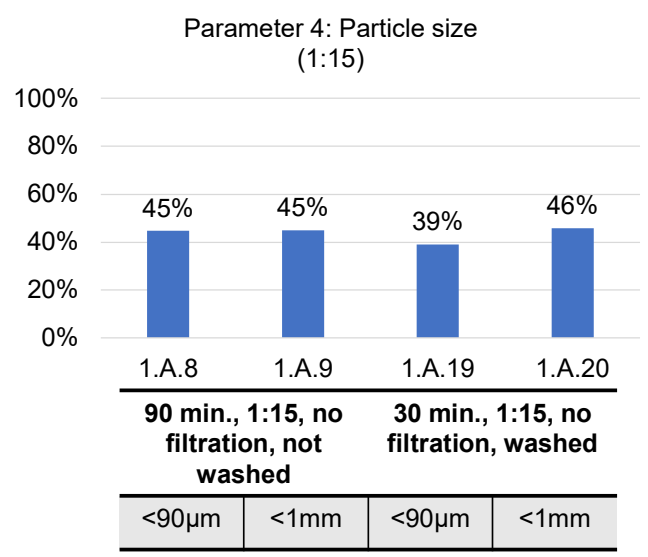

(b)

Figure 13. Detailed observation on achievable lithium yields by neutral leaching $\left(\mathrm{H}_{2} \mathrm{O}\right)$ of heat-treated black mass. The considered parameter is parameter 4: particle size. (a) Dissolution and lithium recovery by comparing trials with a solid/liquid ratio of 1:22.5. (b) Dissolution and lithium recovery by comparing trials with solid/liquid ratio of 1:15.

Comparing trials 1.A.2-1.A.4 with trials 1.A.5-1.A.7 and trial 1.A.8 with trial 1.A.20 reveals that the grain size of the heat-treated black mass does not influence lithium yields. This is particularly interesting for residual lithiation in the anode. It proves that the degree of liberation of lithium is not enhanced by grain size reduction to $<90 \mu \mathrm{m}$. 


\section{Solid/liquid ratio $(\mathrm{g} / \mathrm{mL})$ :}

At a constant grain size and leaching time, higher lithium yields are obtained at a solid/liquid ratio of 1:30 in comparison to 1:10 and 1:15 (see Figure 14a). In addition, an improved lithium recovery is possible when comparing a solid/liquid ratio of 1:30 and 1:22.5 (see Figure 14b). Although the leaching time has not shown an impact, the highest yield is reached with a solid/liquid ratio of 1:30 for $120 \mathrm{~min}$. (see trial 1.A.25). When considering the solubility product of lithium carbonate in the water at $20^{\circ} \mathrm{C}(13.3 \mathrm{~g} / \mathrm{L})$, and a lithium share of $3.7 \mathrm{wt} \%$, a liquid volume of $294 \mathrm{~mL}$ is required for full dissolution, assuming an inserted heat-treated black mass weight of $20 \mathrm{~g}$. Thus, if all lithium is present as lithium carbonate, a solid/liquid ratio of $1: 15 \mathrm{~g} / \mathrm{mL}$ is needed. Since the input material (heat-treated black mass) shows deviations in lithium shares and phases, the findings of a 1:30 solid/liquid ratio are supported. This means that an excess of $\mathrm{H}_{2} \mathrm{O}$ is needed for high lithium dissolution. In Figure 14, examples of the solid/liquid ratio's impact on lithium yields are given. More trial comparisons would be 1.A.11 with a yield of $38 \%$ at a ratio of 1:10, and 1.A.10 with a yield of $44 \%$ at a ratio of 1:15. There are also trial combinations where an increase of the solid/liquid ratio leads to equal lithium yields (e.g., 1.A.15 with 1.A.9, leading to $45 \%$ lithium yield), but generally, yields of $>60 \%$ can be reached only when having $20 \mathrm{~g} / 600 \mathrm{~mL}(1: 30)$.

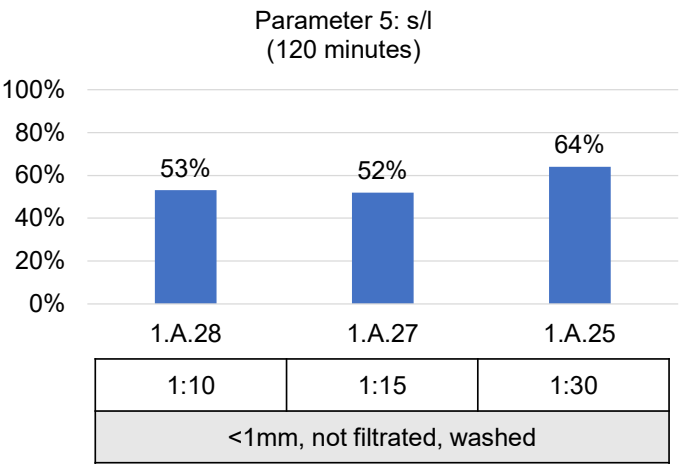

(a)

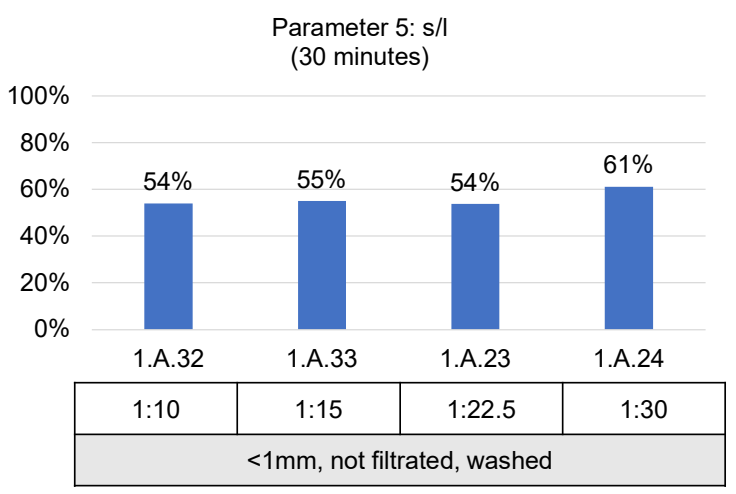

(b)

Figure 14. Detailed observation on achievable lithium yields by neutral leaching $\left(\mathrm{H}_{2} \mathrm{O}\right)$ of heat-treated black mass. The considered parameter is parameter 5: particle size. (a) Dissolution and lithium recovery by comparing trials with a solid/liquid ratio of 1:22.5. (b) Dissolution and lithium recovery by comparing trials with solid/liquid ratio of 1:15.

\section{Pyrolysis temperature:}

The pyrolysis temperature plays an important role in lithium recovery, as can be seen in Figure 15. Here, the difference between a 501 and a $603^{\circ} \mathrm{C}$ pyrolyzed material is pointed out. Reaching higher temperatures leads to different phase transformations within the battery cells. The impact on lithium leaching efficiency and lithium yield as solid lithium carbonate is proven by different scenarios:

Here, both grain size and leaching time do not show a significant impact on the yield. The solid/liquid ratio, along with the washing of the C-filter cake and the solid-liquidseparation method (filtration vs. full boiling), seems to play an important role in this context. Up to $64 \%$ of lithium can be recovered as lithium carbonate. In addition, the parameter pyrolysis temperature has an impact on the lithium yield. Lithium yields by leaching heat-treated black mass without preliminary pyrolysis were not satisfying; hence, these first trials are not shown in this manuscript. It must be recalled that the pyrolysis trials at Ar-atmosphere were operated at higher temperatures than the $\mathrm{CO}_{2}$ and $\mathrm{Ar}+\mathrm{O}_{2}$ pyrolysis trials. 


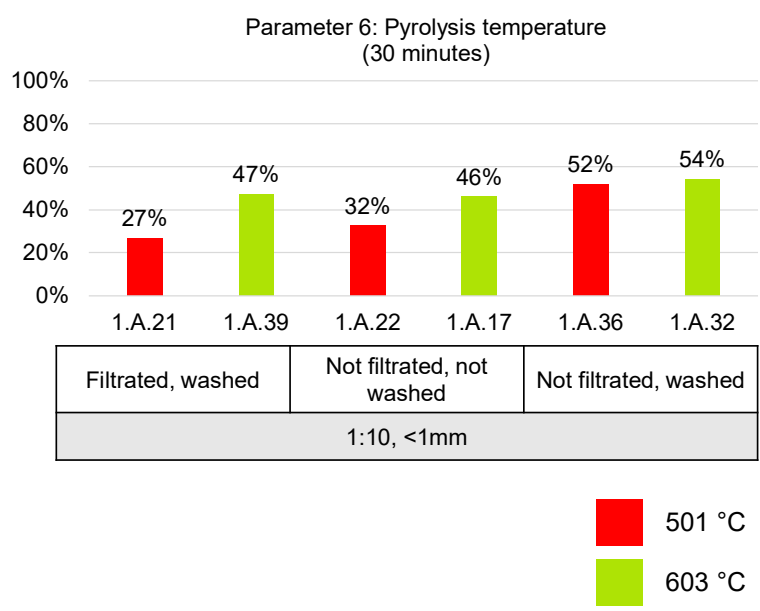

(a)

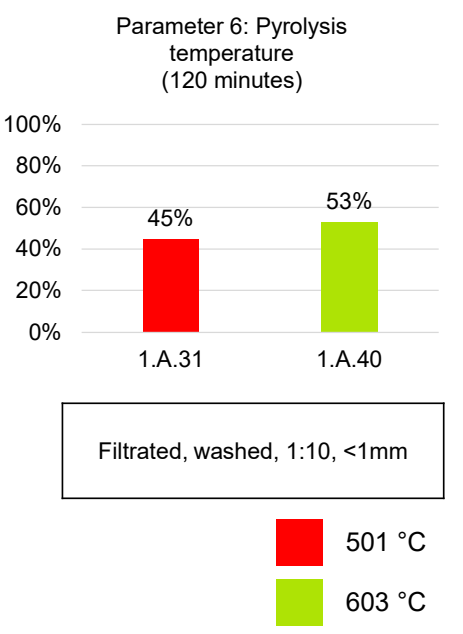

(b)

Figure 15. Detailed observation on achievable lithium yields by neutral leaching $\left(\mathrm{H}_{2} \mathrm{O}\right)$ of heat-treated black mass. The considered parameter is parameter 6: particle size. (a) Dissolution and lithium recovery by comparing trials with a solid/liquid ratio of 1:22.5. (b) Dissolution and lithium recovery by comparing trials with solid/liquid ratio of 1:15.

For evaluating autoclave trials in terms of lithium mobilization, the lithium yields from neutral leaching are to be contrasted to the lithium yields from autoclave trials using the same parameters (see Figure 16). Since the autoclave trials were operated at a holding time of $120 \mathrm{~min}$, the following diagram points out the achievable maximum lithium yields dependent on the pyrolysis temperature/atmosphere and solid/liquid ratio examined in the autoclave trials. Hereby, a direct comparison between neutral leaching (experimental series 1.A, 1.O and 1.C) and autoclave carbonation (2.A) can be performed.

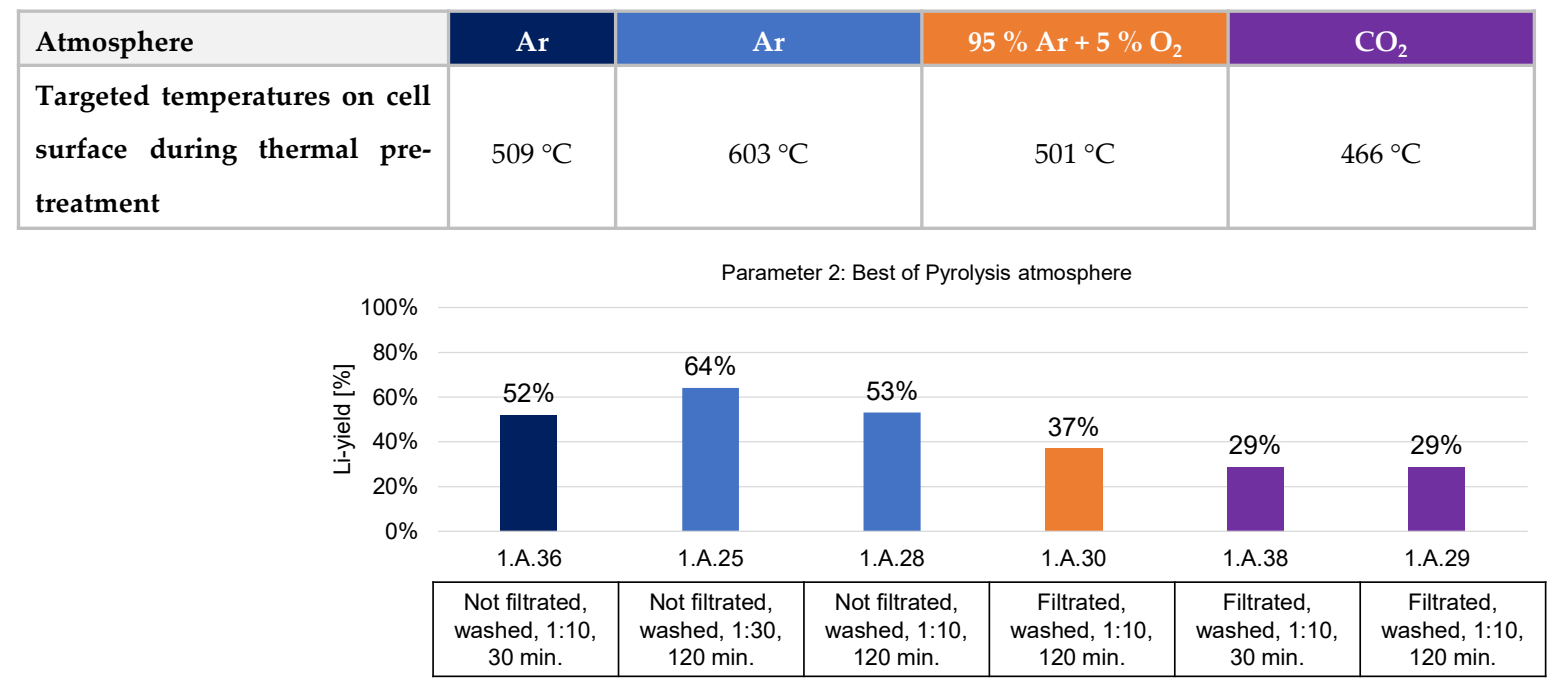

Figure 16. Best of lithium yields dependent on the pyrolysis atmospheres and temperatures. 1.A.36 has not been leached for $120 \mathrm{~min}$, yet.

Since the focus of this study was the Ar-pyrolyzed material since showing the best neutral leaching results, only for this material the solid/liquid ratios were examined in the autoclave trials (1:10, 1:15, 1:30) (series 2.A, 2.O and 2.C). The $\mathrm{CO}_{2}-$ and $\mathrm{Ar}+\mathrm{O}_{2}$ -the pyrolyzed black mass was only treated in the autoclave carbonation set up with a solid/liquid ratio of 1:10 (2.O and 2.C). Hence, Figure 17 sums up the maximum yields of neutral leaching dependent on the pyrolysis parameters examined so far: 


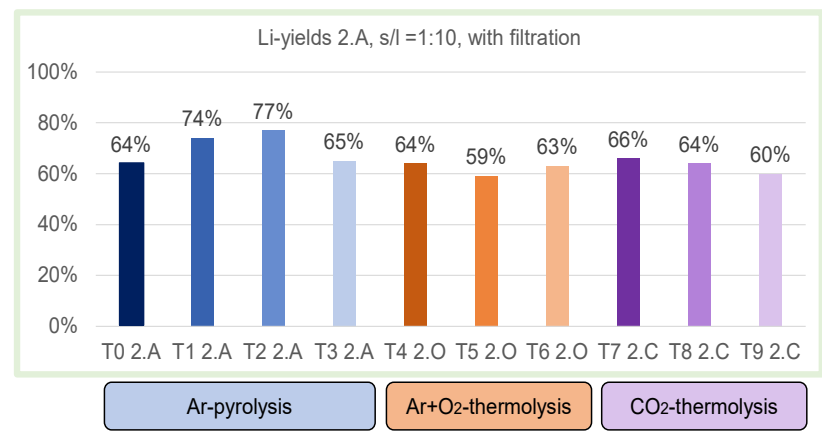

Figure 17. Lithium yields obtained by autoclave carbonation with a solid/liquid ratio of 1:10 for trials series 2.A (T0-T3, blue), $2 . \mathrm{O}$ (T4-T6, orange) and 2.C (T7-9, violet). Trial T0 2.A stands for an Ar-pyrolysis at $509^{\circ} \mathrm{C}$, whereas T1-T3 2.A stands for an Ar-pyrolysis at $603{ }^{\circ} \mathrm{C}$.

\subsection{Carbonation by Supercritical $\mathrm{CO}_{2}$}

Finally, the obtained lithium yields when using autoclave treatments with an s/1 ratio of 1:10 for lithium carbonation can be derived from Figure 17.

Hence, a direct comparison between the atmospheres of the thermal treatments shows the following results: The $509^{\circ} \mathrm{C}$ Ar-pyrolysis, that the autoclave can make a $12 \%$ difference in lithium yield. In comparison to the $603{ }^{\circ} \mathrm{C}$ Ar-pyrolysis, this difference can reach up to $24 \%$ with the correct parameter combination ( $120 \mathrm{~min}$.). For the $\mathrm{Ar}+\mathrm{O}_{2}$-pyrolysis, which is here indicated as thermolysis since comprising $\mathrm{O}_{2}$ in the atmosphere, the increased lithium yield comprises up to $27 \%$. For the $\mathrm{CO}_{2}$-pyrolysis, the obtained difference in lithium yield comprises up to $37 \%$. This indicates higher lithium yields for reductive pyrolysis atmosphere $\left(\mathrm{CO}_{2}\right.$ vs. Ar-atmosphere at $\left.\sim 500{ }^{\circ} \mathrm{C}\right)$ and a stronger impact of autoclave carbonation when dealing with a not fully decomposed heat-treated black mass. This correlation needs further investigations in the future.

The elemental lithium distribution and the lithium carbonate impurities are shown exemplarily for the trial series 1.A with a solid/liquid ratio of 1:10. In Figure 18, the largest part of lithium remains in the heat-treated black mass after leaching. Moreover, the main impurity of the recovered lithium carbonate is fluorine, followed by phosphorous. This can be explained by the presence of $\mathrm{LiF}$ in the heat-treated black mass. It should be noted that the value "Li in filtrate" does only occur within neutral leaching and autoclave trials T0-T9 and T21 and T22, which have conducted a filtration.

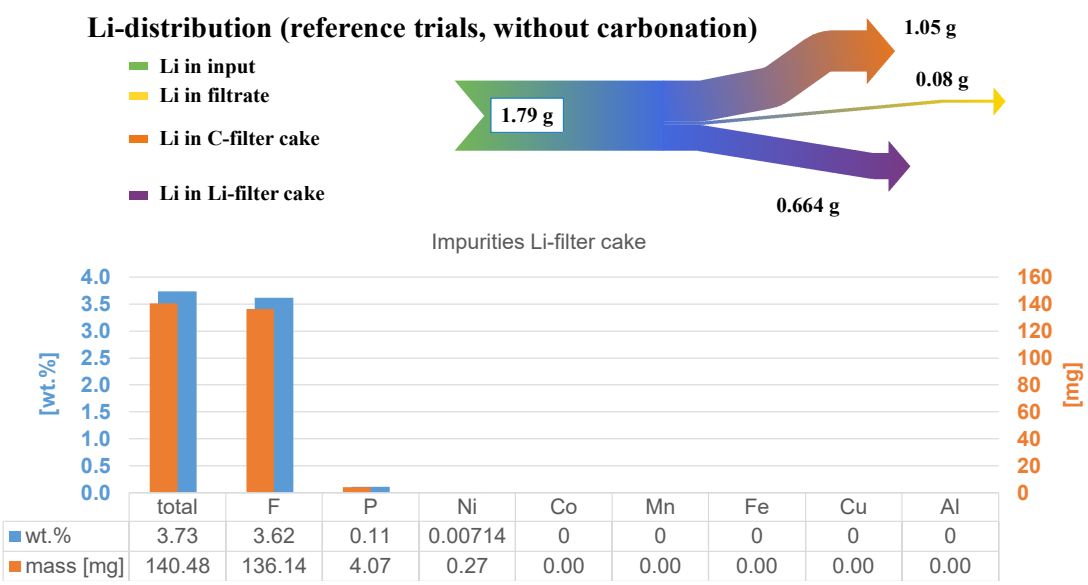

Figure 18. Lithium distribution without autoclave carbonation as exemplary data from the parameter set 1.A.1 by ICP-OES. (Above): Ar-pyrolysis in combination with neutral leaching at a solid/liquid ratio of 1:10. (Below): Matching impurities within the lithium filter cake by ICP-OES and lithium carbonate impurities. 
Figure 19 shows the improvement in Li distribution when applying autoclave carbonation. Trials series 2.A was selected since the neutral leaching trials of Ar-pyrolyzed active mass at $600{ }^{\circ} \mathrm{C}$ has shown the best yields. Trial series 2.A represents Ar-pyrolysis, with a $\mathrm{CO}_{2}+\mathrm{H}_{2} \mathrm{O}$ autoclave-reaction, and also a solid/liquid ratio of 1:10 in the autoclave. In this case, the share in the residual heat-treated black mass filter cake is significantly lower, which is a proof-of-concept of the carbonation mechanism within the autoclave.

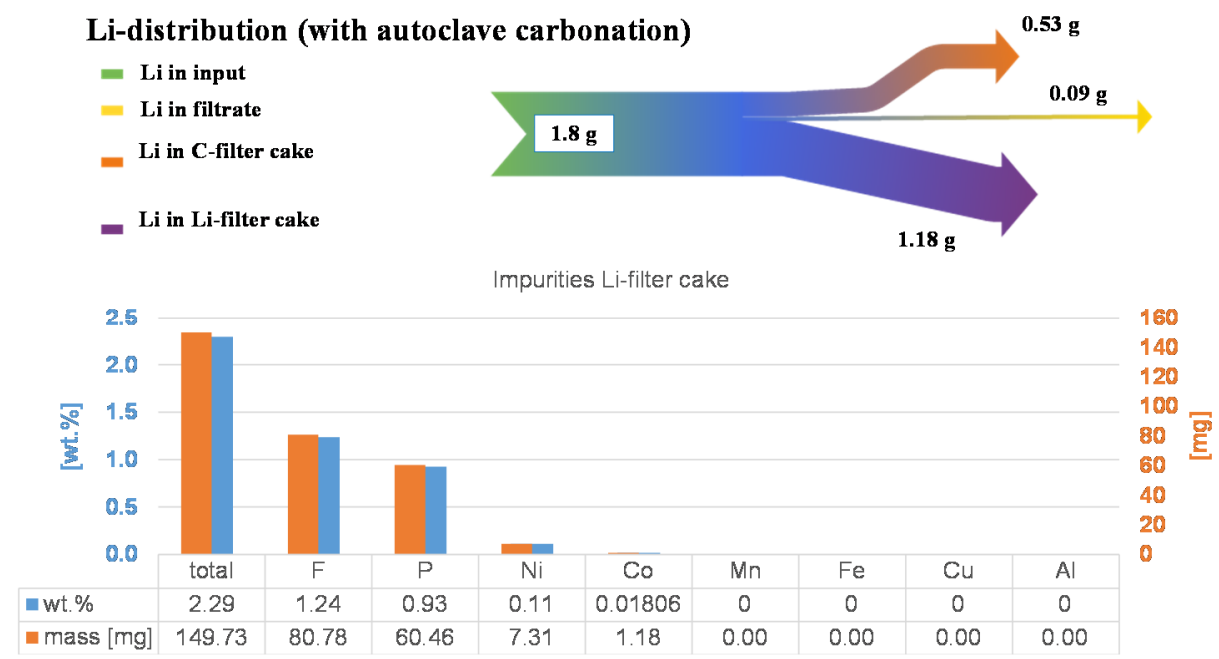

Figure 19. Lithium distribution with autoclave carbonation as exemplary data from the parameter set 2.A (T2 2.A) by ICP-OES. (Above): Ar-pyrolysis in combination with neutral leaching with carbonation by supercritical $\mathrm{CO}_{2}+$ aqueous medium at a solid/liquid ratio of 1:10). (Below): matching impurities within the lithium filter cake.

Hence, impurities in the range of $2-4$ wt.\% can be derived. An XRD-evaluation gives more information on the arising phases within the heat-treated black mass, the C-filter cake and the lithium carbonate filter cake (see Figure 20). This is represented here exemplarily by the $603{ }^{\circ} \mathrm{C}$-Ar-pyrolyzed samples, thus for trial series 2.A, also with a solid/liquid ratio of $1: 10$. One main finding is the removal of $\mathrm{Li}_{2} \mathrm{CO}_{3}$, present in the heat-treated black mass, from the C-filter cake. This is an indicator for the removal of water-soluble compounds. In contrast to Figure 20, XRD-evaluations of $\mathrm{CO}_{2}$-pyrolyzed black mass at $466{ }^{\circ} \mathrm{C}$ and $\mathrm{Ar}+$ $\mathrm{O}_{2}$-pyrolyzed black mass at $501{ }^{\circ} \mathrm{C}$ also detect $\mathrm{LiNiMnO}$ - and the $\mathrm{NiO}$, which stands for an incomplete decomposition of transition metal oxides.

Small amounts of fluorine can be found in the Li-filter cake in the form of LiF. It can be seen that especially fluorine removal is crucial for reaching high lithium carbonate purities fluorine. Figure 20 shows the diffractogram of the heat-treated black mass and the C-and Li-filter cakes (T3 2.A.). X-ray diffraction was performed at room temperature using a STADI P (STOE Darmstadt) powder diffractometer using an IPPSD detector and monochromatic $\mathrm{Cu}-\mathrm{K} \alpha 1$ radiation $\left(\lambda=1.54059 \AA\right.$; flat sample; $1.5 \leq 2 \theta \leq 116^{\circ}$ step rate $0.015^{\circ}$ in $\left.2 \theta\right)$ with a measuring time of $2 \mathrm{~h}$.

$\mathrm{LiF}$ was still present in the C-filter cake; hence, the solid/liquid ratio was optimized. In order to prove influencing factors on the lithium yield by an adjusted solid/liquid ratio, the parameter $1: 15$ (solubility of $13.3 \mathrm{~g} / \mathrm{L}$ lithium carbonate at $20^{\circ} \mathrm{C}$ ) and $1: 30$ (solubility of $7.2 \mathrm{~g} / \mathrm{L}$ lithium carbonate at $100^{\circ} \mathrm{C}$ ) were tested. Moreover, to prove the mechanism of autoclave carbonation, two parameters were examined additionally: autoclave carbonation by Ar-excess pressure (3.A) and direct and dry autoclave carbonation by $\mathrm{CO}_{2}$-excess pressure (4.A). Again, since the Ar-pyrolyzed black mass has shown the highest yields in terms of neutral leaching and in terms of autoclave carbonation, only Ar-pyrolyzed black mass is chosen for the parameter improvements.

Table 5 sums up the parameters for the second autoclave carbonation with solid/liquid ratios of $1: 15$ and 1:30. 


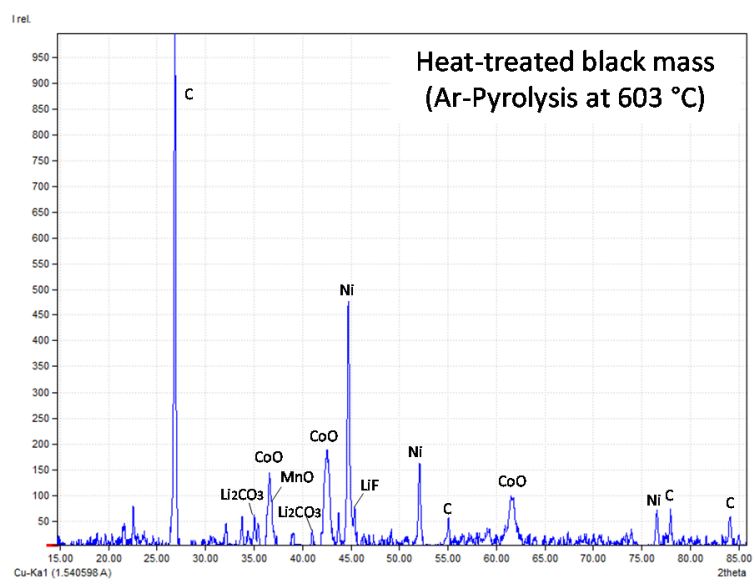

(a)

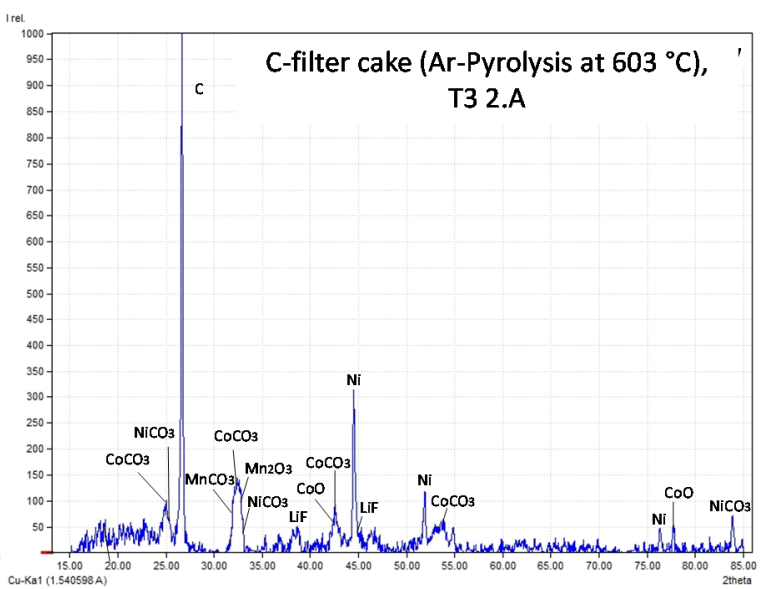

(b)

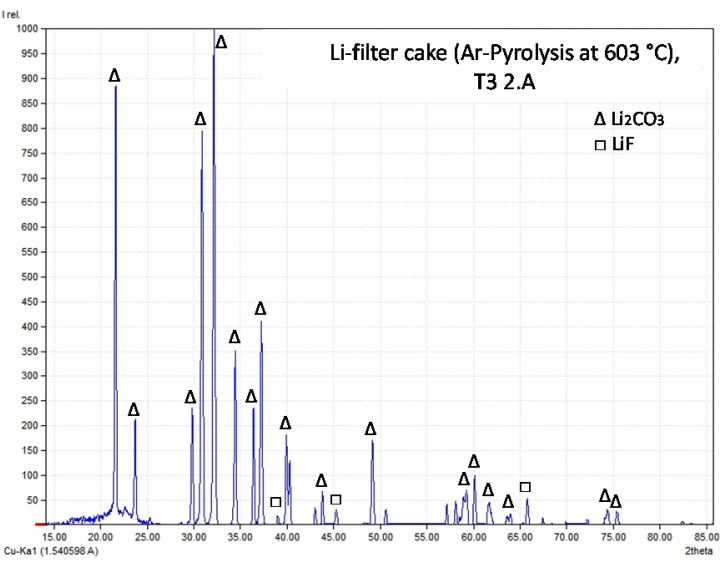

(c)

Figure 20. Graphic pattern of the Ar-pyrolyzed black mass at $603^{\circ} \mathrm{C}(\mathbf{a})$, and the corresponding C-filter cake (b) and Li-filter cake (c) from trial T3 2.A. The XRD-evaluation was performed using the "match!" Software and the COD Inorganics database.

Table 5. Detailed list of parameters examined for autoclave trials T10-T13 (3.A), T14-T16, T18, T19, T21 and T22 (2.A), and T17 and T20 (4.A) with a solid/liquid ratio of 1:15 and 1:30. In T17/20 s/l ratio refers to leaching after autoclave treatment.

\begin{tabular}{ccccc}
\hline & Solid/Liquid Ratio $(\mathbf{s} / \mathbf{l})(\mathbf{g} / \mathbf{m L})$ & $\mathbf{H}_{\mathbf{2}} \mathbf{O}$ in Autoclave & Autoclave Gas & Washing C-Filter Cake with $\mathbf{H}_{\mathbf{2}} \mathbf{O}$ \\
\hline T10 & $1: 15$ & yes & $\mathrm{Ar}$ & no \\
T11 & $1: 15$ & yes & $\mathrm{Ar}$ & no \\
T12 & $1: 15$ & yes & $\mathrm{Ar}$ & no \\
T13 & $1: 15$ & yes & $\mathrm{Ar}$ & no \\
T14 & $1: 15$ & yes & $\mathrm{CO}_{2}$ & yes \\
T15 & $1: 15$ & yes & $\mathrm{CO}_{2}$ & no \\
T16 & $1: 15$ & yes & $\mathrm{CO}_{2}$ & no \\
T17 & $1: 30$ & no & $\mathrm{CO}_{2}$ & yes \\
T18 & $1: 30$ & yes & yes \\
T19 & $1: 30$ & yes & $\mathrm{CO}_{2}$ & yes \\
T20 & $1: 30$ & no & no \\
T21 & $1: 15$ & yes & $\mathrm{CO}_{2}$ & no \\
T22 & $1: 30$ & $\mathrm{CO}_{2}$ & $\mathrm{CO}_{2}$ & \\
\hline
\end{tabular}

The following illustration (see Figure 21) shows the results of autoclave carbonation with solid/liquid ratios of 1:15 and 1:30: 


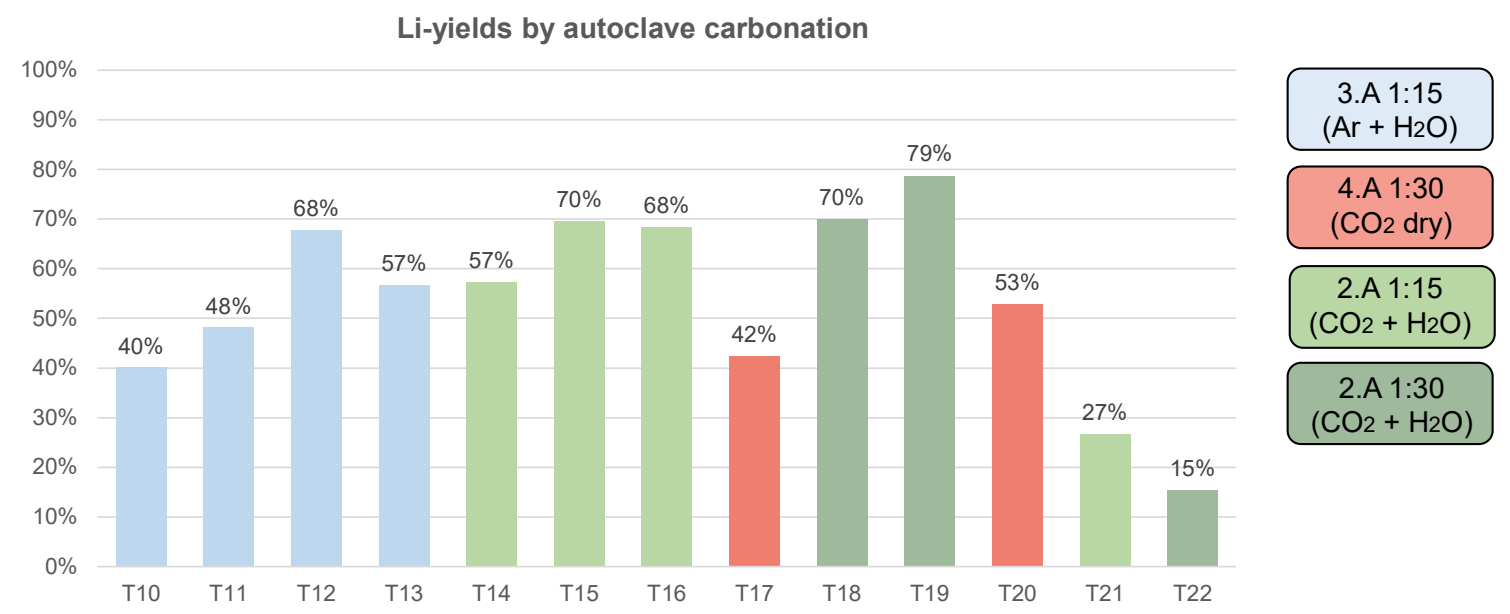

Figure 21. Lithium yields obtained by autoclave carbonation with a solid/liquid ratio of 1:15 (T10-T16, and T21) or 1:30 (T17-T20, and T22). The C-filter-cakes of T15, T18 and T19 were washed, T17 was leached for 5 min and T20 for 90 min. T21 and T22 were filtrated instead of fully boiled.

Thus, the only process window leading to satisfying yields of $79 \%$ is an $\mathrm{s} / \mathrm{l}$ ratio of 1:30 in combination with $\mathrm{CO}_{2}$ carbonation in an aquatic medium. The underlying mechanism seems to be indirect carbonation.

This can be supported by the detected $\mathrm{pH}$ value of all trials. Whereas 1.A.1-1.A.40, $\mathrm{T} 10-\mathrm{T} 13$, and $\mathrm{T} 20$ (without $\mathrm{CO}_{2}$ purging in the liquid) showed a $\mathrm{pH}$ value of 11-12 after charging heat-treated black mass in $\mathrm{H}_{2} \mathrm{O}$, the trials T0-T9. T14-T16, T18/T19 and T21/T22 (with $\mathrm{CO}_{2}$ purging in the liquid) showed a $\mathrm{pH}$ value of 7-8 after charging heat-treated black mass in $\mathrm{H}_{2} \mathrm{O}$. Hence, $\mathrm{CO}_{2}$ was dissolved in the liquid. The generally higher yields in T10-T20 can also be attributed to the avoidance of a second filtration step for recovering lithium. Instead, the solution was boiled until reaching a slurry-state and then was dried in a beaker. Hereby, lithium losses in the residual filtrate are avoided. In addition, when comparing $\mathrm{T} 17$ to $\mathrm{T} 20$, the advantage of a longer leaching time and washing of the carbon filter cake with deionized $\mathrm{H}_{2} \mathrm{O}$ is shown. The washing of the carbon filter cake generally leads to higher yields since dissolved lithium remaining in the filter cakes in the solution can leave the system just by washing. However, comparing T15 to T14 and T16 in terms of $\mathrm{C}$-filter cake washing reveals a rather small impact on the lithium yields (max. $2 \%$ ). When comparing T21 to T14 and to T16, it can be seen that filtrating of the lithium solution is not expedient. This can be explained by the residual lithium dissolution in the filtrate. The comparison between T22 and T18-T19 confirms this relation. T21 and T22 show very low yields. Although the lithium filter cake was filtrated instead of full boiling and the C-filter cake was not washed, their lithium yield shows disproportionally low yields, which can only be explained by heterogeneity in the heat-treated black mass.

\section{Discussion}

This study proves the concept of indirect carbonation for treating lithium-ion battery heat-treated black mass with supercritical $\mathrm{CO}_{2}$. The involvement of supercritical $\mathrm{CO}_{2}$ in terms of lithium carbonate generation is supported by yields comparing Ar-excess pressure and $\mathrm{CO}_{2}$-excess pressure. Moreover, indirect carbonation is shown by comparing a dry autoclave process to a liquid-based autoclave process. The lower $\mathrm{pH}$-value of $\mathrm{pH}=7-8$ when applying $\mathrm{CO}_{2}$ in comparison to $\mathrm{H}_{2} \mathrm{O}$-leaching $(\mathrm{pH}=11-12)$ can lead to the following statements:

1. When leaching heat-treated black mass in $\mathrm{H}_{2} \mathrm{O}$, the solution is basic. This can be attributed to the dissolution of basic phases in the liquid. $\rightarrow \mathrm{LiF}$ and $\mathrm{Li}_{2} \mathrm{CO}_{3}$ could be detected in the heat-treated black mass by $\mathrm{XRD}$; both phases are slightly soluble and therefore are responsible for the elevated $\mathrm{pH}$-value. Although $\mathrm{LiOH}$ and $\mathrm{Li}_{2} \mathrm{O}$ could not be detected via XRD-analysis in the heat-treated black mass, they may be present 
in small amounts since the SEI-layers consist of $\mathrm{Li}_{2} \mathrm{CO}_{3}, \mathrm{LiF}, \mathrm{LiOH}$ and $\mathrm{Li}_{2} \mathrm{O}$ [93]. However, it was shown that $\mathrm{LiF}$ decomposes to $\mathrm{HF}$ and $\mathrm{LiOH}$ in aqueous solutions, which indicates $\mathrm{Li}^{+}+\mathrm{OH}^{-}$in the solution.

2. When leaching heat-treated black mass in $\mathrm{H}_{2} \mathrm{O}$ and adding $\mathrm{CO}_{2}$-gas, the $\mathrm{pH}$ value of the solution decreases to 7-8. Mechanisms are in place, which can be attributed to $\mathrm{CO}_{2}$ and which are leading to a higher lithium leaching efficiency. In the following, hypotheses for the underlying mechanisms are stated:

a. The formation of carbonic acid and thus the formation of $\mathrm{CO}_{3}{ }^{2-}$ and $\mathrm{HCO}_{3}{ }^{-}$ as acidic leaching agents. $\mathrm{CO}_{2}$ is added to a basic solution; it reacts acidic by the release of $\mathrm{H}^{+}$ions. This $\mathrm{pH}$-value decrease can be responsible for a higher leaching efficiency by creating quasi-acidic leaching conditions similar to conventional hydrometallurgy.

b. Recombination of $\mathrm{Li}^{+}$, stemming from non-lithium carbonate phases like $\mathrm{LiF}$, with present $\mathrm{CO}_{3}{ }^{2-}$ or $\mathrm{HCO}_{3}{ }^{-}$. This would entail the following suggested equations (see Equations (19) and (20), schematically shown in Figure 22):

$$
\begin{gathered}
\mathrm{Li}^{+}+\mathrm{CO}_{3}{ }^{2-} \rightarrow \mathrm{Li}_{2} \mathrm{CO}_{3} \\
\mathrm{Li}^{+}+\mathrm{HCO}_{3}{ }^{-} \rightarrow \mathrm{LiHCO}_{3}
\end{gathered}
$$

c. A combination of both mentioned mechanisms. In this way, the dissolution of lithium phases in the heat-treated black mass is promoted by $\mathrm{CO}_{2}$, more lithium ions can be formed to $\mathrm{Li}_{2} \mathrm{CO}_{3}$, and this effect is also promoted by the increased operating temperatures and arising excess pressure.

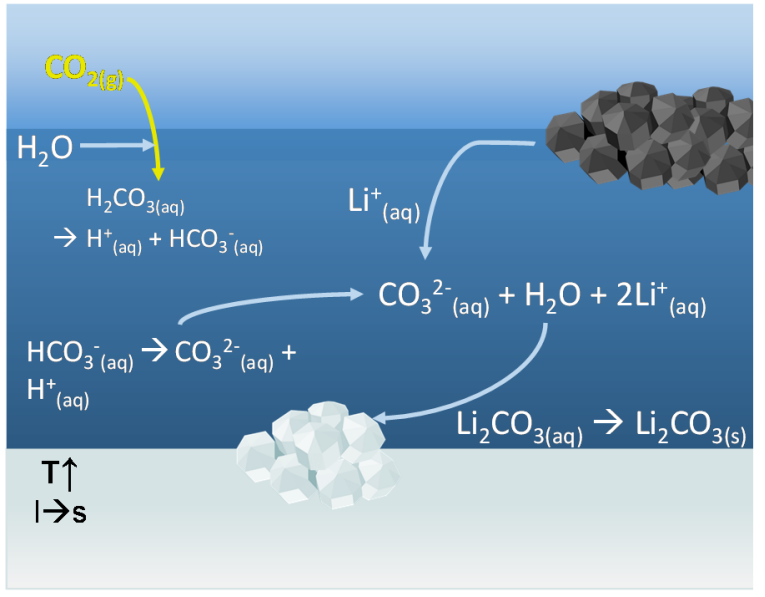

(a)

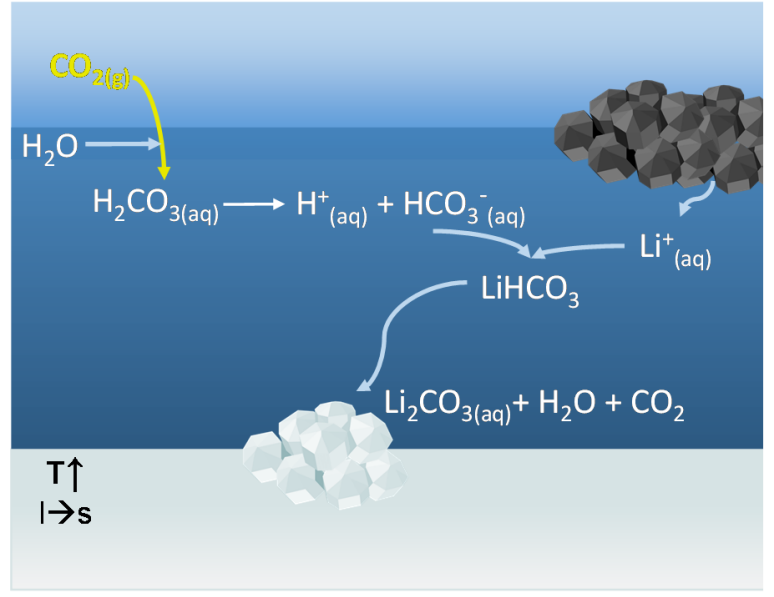

(b)

Figure 22. Schematic process visualization of indirect carbonation promoted by supercritical $\mathrm{CO}_{2}$ based on $\mathrm{CO}_{3}{ }^{2-}$ (a) and $\mathrm{HCO}_{3}^{-}(\mathbf{b})$ in terms of leaching lithium-ion battery heat-treated black mass in deionized water. When increasing the solution's temperature, lithium carbonate is precipitated as a solid lithium salt.

\section{Conclusions}

The presented "ESLR" process, consisting of thermal treatment, mechanical comminution and a sorting step, followed by a subsequent carbonation process, results in the following scientific findings:

Carbonation by supercritical $\mathrm{CO}_{2}$ shows an increased lithium yield of around $15 \%$. This value stems from the difference between a maximum lithium yield in neutral leaching of $64 \%$ and a maximum lithium yield in autoclave carbonation of $79 \%$. When expressing the yield as leaching efficiency, $88 \%$ were reached. The different pyrolysis atmospheres and temperatures show a direct influence on the lithium yield. Further key influencing factors for both $\mathrm{H}_{2} \mathrm{O}$-leaching with and without $\mathrm{CO}_{2}$ are solid/liquid ratio, filter cake washing 
and the lithium extraction method (filtration vs. full boiling). It can be concluded that the "ESLR" process shows benefits in comparison to simple $\mathrm{H}_{2} \mathrm{O}$-leaching and that the mechanism for indirect carbonation is beneficial. Moreover, the "ESLR" process is a separate step to ease $\mathrm{Ni} / \mathrm{Co} / \mathrm{Mn}$ recovery and to enhance the degree of lithium mobilization. Hence, the resulting lithium-reduced filter cake (C-filter cake) can be integrated into existing hydroor pyrometallurgical steps.

The process of technology relevance is shown by the following specific benefits in contrast to the state-of-the-art:

- Conventional lithium carbonation, e.g., by $\mathrm{Na}_{2} \mathrm{CO}_{3}$, is avoided, and no further chemicals are required, making lithium recovery more environmentally friendly;

- Subsequent treating the C-filter cake hydrometallurgically for metal extraction ( $\mathrm{Ni}$, $\mathrm{Co}, \ldots$ ) requires fewer leaching agents because the input mass is reduced, and hence, fewer additives for $\mathrm{pH}$-adjustments are needed;

- Moreover, in comparison to conventional hydrometallurgical lithium recovery, the liquid volume can be fully evaporated (filtration vs. full boiling). Hereby, no lithium remains in the solution. This is possible since no enhancement of salinity is caused in "ESLR";

- Lithium losses in various byproducts of chemical solution purification and metal winning steps are avoided;

- Costly lithium extraction from a pyrometallurgy treatment and hydrometallurgical purifying of slags is also avoided.

In contrast to other studies, the sequence of thermal and mechanical treatment is inverted. In this study, battery cells are first thermally treated and then shredded to extract heat-treated black mass. This procedure is safer due to the avoidance of ignition during shredding.

Comparing lithium yields by $\mathrm{H}_{2} \mathrm{O}$-leaching in this study to literature, the following statements can be given: In [74], 66\% of lithium from NMC black mass are obtained by shredding, then thermal treating and $\mathrm{H}_{2} \mathrm{O}$-leaching. Here, the authors rather focus on LMO-cells and report on one trial, only reaching $66 \%$ [74]. However, in this paper, $64 \%$ could be recovered by thermal treatment with subsequent shredding and $\mathrm{H}_{2} \mathrm{O}$-leaching at a thermal treatment by $100{ }^{\circ} \mathrm{C}$ lower than Xiao et al. and without costly vacuum operations. In comparison to [46,47], where $40 \%$ of lithium could be recovered by shredding, thermal treatment and $\mathrm{H}_{2} \mathrm{O}$-leaching of cathode black mass, the yield in this study are up to $24 \%$ higher.

A comparison of lithium yields by $\mathrm{H}_{2} \mathrm{O}$-leaching in combination with $\mathrm{CO}_{2}$ (indirect carbonation) is not straightforward since there is no study in place using the whole black mass from NMC-cells for this process. However, by using cathode black mass with lignite, $85 \%$ is reached, whereas, in this study, $79 \%$ are reached. This difference might be attributable to the neglection of anode material and/or the use of lignite instead in [46,47]. In comparison to [90], the yields in this study are $19 \%$ higher (60\% vs. $79 \%)$, but yield and matching parameters are given based on a lithium ore treatment. Only the transferability to black mass is mentioned. However, this study also uses heat-treated black mass in contrast to [90]. In comparison to [91], and avoidance of electrodialysis in a $\mathrm{Li}_{2} \mathrm{SO}_{4}$-solution and of carbonation reagents could be reached.

A comparison of lithium yields by a thermal $\mathrm{CO}_{2}$-treatment with subsequent $\mathrm{H}_{2} \mathrm{O}$ leaching (direct carbonation) is hardly possible since the autoclave process in this study worked at $\mathrm{T}_{\max }=230^{\circ} \mathrm{C}$, whereas literature focuses on elevated temperatures $\left(\sim 650-800{ }^{\circ} \mathrm{C}[73]\right)$ with $\mathrm{CO}_{2}$ as purging instead of excess pressure; moreover, no yield calculation is given [73].

In this study, a proof-of-concept regarding the indirect carbonation using supercritical $\mathrm{CO}_{2}$ in an autoclave could be shown.

The most important follow-up research comprises a further enhancement of lithium yields to a value of $>90 \%$, which is necessary to make the "ESLR" a competitive process option. Then, $\mathrm{CO}_{2}$-driven carbonation without supercritical $\mathrm{CO}_{2}$, but by $\mathrm{CO}_{2}$-gas purging instead. This is crucial because the combination of thermal pretreatment and an autoclave 
treatment comprise high energy requirements. However, as reported in Section 1.1.1, thermal conditioning is also beneficial for hydrometallurgical treatment. Hence, the connected energy demands cannot particularly and only be counted for the "ESLR" process. First trials with $\mathrm{CO}_{2}$-gas instead of $\mathrm{SCCO}_{2}$ have shown lithium yields around $70 \%$. Hereby, insights into the role of excess pressure $(73.8 \mathrm{bar})$ and high temperatures $\left(150{ }^{\circ} \mathrm{C}\right)$ are possible. Moreover, this setup would imply economic benefits due to the avoidance of high-pressure operations. This will be one topic of "Early-Stage Recovery of Lithium from Tailored Thermal Conditioned Black Mass Part II: Mobilizing Lithium via gaseous $\mathrm{CO}_{2}$-Carbonation". Moreover, a refining of the $\mathrm{C}$-filter cake by flotation or acidic leaching should be tested. Upscaling is planned for future research to test possible scale effects due to losses on equipment surfaces, for example, on beakers after boiling the lithium filtrate. In addition, a suitable development for removing fluorine from the heat-treated black mass, filtrates and filter cakes would be an important tool for hazardous-free processing, which would not harm the used equipment by developing HF-gas. Moreover, experimental series 3.O/3.C and 4.O/4.C are to be performed. Moreover, the heat-treated black mass-producing pyrolysis was conducted with a holding time of $60 \mathrm{~min}$. This may be optimized as well to find the perfect match in terms of temperature and holding time.

Author Contributions: Conceptualization, L.S. and B.F.; methodology, L.S.; validation, L.S., T.S. and B.F.; formal analysis, L.S. and T.S.; investigation, L.S. and T.S.; resources, L.S. and T.S.; data curation, L.S. and T.S.; writing—original draft preparation, L.S.; writing—review and editing, L.S.; visualization, L.S.; supervision, B.F. All authors have read and agreed to the published version of the manuscript.

Funding: This research was partly funded by the Research Council of Norway in the frame of the LIBRES project (project number 282328).

Institutional Review Board Statement: Not applicable.

Data Availability Statement: The data presented in this study are available on request from the corresponding author. The data are not publicly available since being part of active research.

Acknowledgments: In cooperation with Access e.V. EDS-analyses were enabled, and in cooperation with the Institute of Inorganic Chemistry (IAC) at RWTH Aachen, XRD-measurements were possible. We are grateful for the support of both partners.

Conflicts of Interest: The authors declare no conflict of interest.

\section{References}

1. Wang, X.; Gaustad, G.; Babbitt, C.W.; Richa, K. Economies of scale for future lithium-ion battery recycling infrastructure. Resour. Conserv. Recycl. 2014, 83, 53-62. [CrossRef]

2. Zheng, X.; Zhu, Z.; Lin, X.; Zhang, Y.; He, Y.; Cao, H.; Sun, Z. A Mini-Review on Metal Recycling from Spent Lithium Ion Batteries. Engineering 2018, 4, 361-370. [CrossRef]

3. Pinegar, H.; Smith, Y.R. Recycling of End-of-Life Lithium Ion Batteries, Part I: Commercial Processes. J. Sustain. Metall. 2019, 5, 402-416. [CrossRef]

4. Boyden, A.; Soo, V.K.; Doolan, M. The Environmental Impacts of Recycling Portable Lithium-Ion Batteries. Procedia CIRP 2016, 48, 188-193. [CrossRef]

5. Zhao, S.; He, W.; Li, G. Recycling Technology and Principle of Spent Lithium-Ion Battery. In Recycling of Spent Lithium-Ion Batteries; An, L., Ed.; Springer International Publishing: Cham, Switzerland, 2019; pp. 1-26, ISBN 978-3-030-31833-8.

6. Becker, J.; Beverungen, D.; Winter, M.; Menne, S. Umwidmung und Weiterverwendung von Traktionsbatterien; Springer Fachmedien Wiesbaden: Wiesbaden, Germany, 2019; ISBN 978-3-658-21020-5.

7. Werner, D.; Peuker, U.A.; Mütze, T. Recycling Chain for Spent Lithium-Ion Batteries. Metals 2020, 10, 316. [CrossRef]

8. Harper, G.; Sommerville, R.; Kendrick, E.; Driscoll, L.; Slater, P.; Stolkin, R.; Walton, A.; Christensen, P.; Heidrich, O.; Lambert, S.; et al. Recycling lithium-ion batteries from electric vehicles. Nature 2019, 575, 75-86. [CrossRef]

9. Pinegar, H.; Smith, Y.R. Recycling of End-of-Life Lithium-Ion Batteries, Part II: Laboratory-Scale Research Developments in Mechanical, Thermal, and Leaching Treatments. J. Sustain. Metall. 2020, 6, 142-160. [CrossRef]

10. Bai, Y.; Muralidharan, N.; Sun, Y.-K.; Passerini, S.; Stanley Whittingham, M.; Belharouak, I. Energy and environmental aspects in recycling lithium-ion batteries: Concept of Battery Identity Global Passport. Mater. Today 2020, 41, 304-315. [CrossRef]

11. Peters, J.F.; Simon, B.; Rodriguez-Garcia, G.; Weil, M. Building a common base for LCA benchmarking of Li-Ion batteries. In Proceedings of the SETAC 26th Annual Meeting, Nantes, France, 22-26 May 2016. 
12. Dunn, J.B.; Gaines, L.; Kelly, J.C.; Gallagher, K.G. Life Cycle Analysis Summary for Automotive Lithiumion Battery Production and Recycling. In Rewas 2016: Towards Materials Resource Sustainability; John Wiley \& Sons, Ltd.: Hoboken, NJ, USA, 2016; pp. 73-79.

13. Martens, H.; Goldmann, D. Recyclingtechnik; Fachbuch für Lehre und Praxis, 2. Aufl; Springer Fachmedien Wiesbaden: Wiesbaden, Germany, 2016; ISBN 978-3-658-02786-5.

14. Diekmann, J.; Sander, S.; Sellin, G.; Petermann, M.; Kwade, A. Crushing of Battery Modules and Cells. In Recycling of Lithium-Ion Batteries; Kwade, A., Diekmann, J., Eds.; Springer International Publishing: Cham, Switzerland, 2018; pp. 127-138, ISBN 978-3319-70571-2.

15. Sojka, R.T. Sichere Aufbereitung von Lithium-basierten Batterien durch thermische Konditionierung. Safe treatment of Lithiumbased Batteries through Thermal Conditioning. In Recycling und Sekundärrohstoffe, Band 13; Thomé-Kozmiensky, E., Holm, O., Friedrich, B., Goldmann, D., Eds.; Thomé-Kozmiensky Verlag GmbH: Nietwerder, Germany, 2020; pp. 506-523, ISBN 978-3944310-51-0.

16. Zhang, G.; Du, Z.; He, Y.; Wang, H.; Xie, W.; Zhang, T. A Sustainable Process for the Recovery of Anode and Cathode Materials Derived from Spent Lithium-Ion Batteries. Sustainability 2019, 11, 2363. [CrossRef]

17. Jiang, H.; Emmett, R.K.; Roberts, M.E. Thermally induced deactivation of lithium-ion batteries using temperature-responsive interfaces. Ionics 2019, 25, 2453-2457. [CrossRef]

18. Meshram, P.; Pandey, B.D.; Mankhand, T.R. Recovery of valuable metals from cathodic active material of spent lithium ion batteries: Leaching and kinetic aspects. Waste Manag. 2015, 45, 306-313. [CrossRef] [PubMed]

19. Lombardo, G.; Ebin, B.; St. J. Foreman, M.R.; Steenari, B.-M.; Petranikova, M. Chemical Transformations in Li-Ion Battery Electrode Materials by Carbothermic Reduction. ACS Sustain. Chem. Eng. 2019, 7, 13668-13679. [CrossRef]

20. Ekberg, C.; Petranikova, M. Lithium Batteries Recycling. In Lithium Process Chemistry. Resources, Extraction, Batteries, and Recycling; Chagnes, A., Światowska, J., Eds.; Elsevier: Amsterdam, The Netherlands, 2015; pp. 233-267, ISBN 9780128014172.

21. Sun, L.; Qiu, K. Vacuum pyrolysis and hydrometallurgical process for the recovery of valuable metals from spent lithium-ion batteries. J. Hazard. Mater. 2011, 194, 378-384. [CrossRef]

22. Träger, T.; Friedrich, B.; Weyhe, R. Recovery Concept of Value Metals from Automotive Lithium-Ion Batteries. Chem. Ing. Tech. 2015, 87, 1550-1557. [CrossRef]

23. Stallmeister, C.; Schwich, L.; Friedrich, B. Early-Stage Li-Removal-Vermeidung von Lithiumverlusten im Zuge der Thermischen und Chemischen Recyclingrouten von Batterien. In Recycling und Sekundärrohstoffe, Band 13; Thomé-Kozmiensky, E., Holm, O., Friedrich, B., Goldmann, D., Eds.; Thomé-Kozmiensky Verlag GmbH: Nietwerder, Germany, 2020; pp. 545-557, ISBN 978-3944310-51-0.

24. Vest, M. Weiterentwicklung des Pyrometallurgischen IME Recyclingverfahrens für Li-Ionen Batterien von Elektrofahrzeugen. Ph.D. Thesis, Shaker Verlag GmbH, Aachen, Germany, 2016.

25. Wang, H.; Friedrich, B. Development of a Highly Efficient Hydrometallurgical Recycling Process for Automotive Li-Ion Batteries. J. Sustain. Metall. 2015, 1, 168-178. [CrossRef]

26. Chen, Y.; Liu, N.; Jie, Y.; Hu, F.; Li, Y.; Wilson, B.P.; Xi, Y.; Lai, Y.; Yang, S. Toxicity Identification and Evolution Mechanism of Thermolysis-Driven Gas Emissions from Cathodes of Spent Lithium-Ion Batteries. ACS Sustain. Chem. Eng. 2019, 7, 18228-18235. [CrossRef]

27. Shin, S.M.; Kim, N.H.; Sohn, J.S.; Yang, D.H.; Kim, Y.H. Development of a metal recovery process from Li-ion battery wastes. Hydrometallurgy 2005, 79, 172-181. [CrossRef]

28. Yang, Y.; Song, S.; Lei, S.; Sun, W.; Hou, H.; Jiang, F.; Ji, X.; Zhao, W.; Hu, Y. A process for combination of recycling lithium and regenerating graphite from spent lithium-ion battery. Waste Manag. 2019, 85, 529-537. [CrossRef]

29. Or, T.; Gourley, S.W.D.; Kaliyappan, K.; Yu, A.; Chen, Z. Recycling of mixed cathode lithium-ion batteries for electric vehicles: Current status and future outlook. Carbon Energy 2020, 61, 1. [CrossRef]

30. Essay, P.; Foxworth, C.; Strauss, C.; Torres, A. Corby Anderson. Hydrometallurgical Recovery of Materials from Lithium-ion Batteries. 2012. Available online: https://www.researchgate.net/publication/302285317_Hydrometallurgical_Recovery_of_ Materials_from_Lithium-ion_Batteries (accessed on 19 January 2021).

31. Liu, P.; Xiao, L.; Chen, Y.; Tang, Y.; Wu, J.; Chen, H. Recovering valuable metals from LiNixCoyMn1-x-yO2 cathode materials of spent lithium ion batteries via a combination of reduction roasting and stepwise leaching. J. Alloys Compd. 2019, 783, 743-752. [CrossRef]

32. Li, L.; Zhang, X.; Li, M.; Chen, R.; Wu, F.; Amine, K.; Lu, J. The Recycling of Spent Lithium-Ion Batteries: A Review of Current Processes and Technologies. Electrochem. Energy Rev. 2018, 1, 461-482. [CrossRef]

33. Huang, B.; Pan, Z.; Su, X.; An, L. Recycling of lithium-ion batteries: Recent advances and perspectives. J. Power Sources 2018, 399, 274-286. [CrossRef]

34. Meshram, P.; Pandey, B.D.; Mankhand, T.R. Extraction of lithium from primary and secondary sources by pre-treatment, leaching and separation: A comprehensive review. Hydrometallurgy 2014, 150, 192-208. [CrossRef]

35. Li, L.; Bian, Y.; Zhang, X.; Xue, Q.; Fan, E.; Wu, F.; Chen, R. Economical recycling process for spent lithium-ion batteries and macro- and micro-scale mechanistic study. J. Power Sources 2018, 377, 70-79. [CrossRef]

36. Barik, S.P.; Prabaharan, G.; Kumar, L. Leaching and separation of Co and Mn from electrode materials of spent lithium-ion batteries using hydrochloric acid: Laboratory and pilot scale study. J. Clean. Prod. 2017, 147, 37-43. [CrossRef] 
37. Chen, X.; Zhou, T. Hydrometallurgical process for the recovery of metal values from spent lithium-ion batteries in citric acid media. Waste Manag. Res. 2014, 32, 1083-1093. [CrossRef]

38. Wang, R.-C.; Lin, Y.-C.; Wu, S.-H. A novel recovery process of metal values from the cathode active materials of the lithium-ion secondary batteries. Hydrometallurgy 2009, 99, 194-201. [CrossRef]

39. Nayl, A.A.; Elkhashab, R.A.; Badawy, S.M.; El-Khateeb, M.A. Acid leaching of mixed spent Li-ion batteries. Arab. J. Chem. 2017, 10, S3632-S3639. [CrossRef]

40. Sattar, R.; Ilyas, S.; Bhatti, H.N.; Ghaffar, A. Resource recovery of critically-rare metals by hydrometallurgical recycling of spent lithium ion batteries. Sep. Purif. Technol. 2019, 209, 725-733. [CrossRef]

41. Gao, W.; Zhang, X.; Zheng, X.; Lin, X.; Cao, H.; Zhang, Y.; Sun, Z. Lithium Carbonate Recovery from Cathode Scrap of Spent Lithium-Ion Battery: A Closed-Loop Process. Environ. Sci. Technol. 2017, 51, 1662-1669. [CrossRef]

42. Stopic, S.; Dertmann, C.; Modolo, G.; Kegler, P.; Neumeier, S.; Kremer, D.; Wotruba, H.; Etzold, S.; Telle, R.; Rosani, D.; et al. Synthesis of Magnesium Carbonate via Carbonation under High Pressure in an Autoclave. Metals 2018, 8, 993. [CrossRef]

43. Rahmani, O.; Highfield, J.; Junin, R.; Tyrer, M.; Pour, A.B. Experimental Investigation and Simplistic Geochemical Modeling of $\mathrm{CO}_{2}$ Mineral Carbonation Using the Mount Tawai Peridotite. Molecules 2016, 21, 353. [CrossRef] [PubMed]

44. Daval, D.; Martinez, I.; Guigner, J.-M.; Hellmann, R.; Corvisier, J.; Findling, N.; Dominici, C.; Goffe, B.; Guyot, F. Mechanism of wollastonite carbonation deduced from micro- to nanometer length scale observations. Am. Mineral. 2009, 94, 1707-1726. [CrossRef]

45. Haug, T.A. Dissolution and Carbonation of Mechanically Activated Olivine. Investigating $\mathrm{CO}_{2}$ Sequestration Possibilities. Ph.D. Thesis, Norwegian University of Science and Technology, Trondheim, Norway, 2010.

46. Hu, J.; Zhang, J.; Li, H.; Chen, Y.; Wang, C. A promising approach for the recovery of high value-added metals from spent lithium-ion batteries. J. Power Sources 2017, 351, 192-199. [CrossRef]

47. Zhang, J.; Hu, J.; Zhang, W.; Chen, Y.; Wang, C. Efficient and economical recovery of lithium, cobalt, nickel, manganese from cathode scrap of spent lithium-ion batteries. J. Clean. Prod. 2018, 204, 437-446. [CrossRef]

48. Kunzler, C.; Alves, N.; Pereira, E.; Nienczewski, J.; Ligabue, R.; Einloft, S.; Dullius, J. $\mathrm{CO}_{2}$ storage with indirect carbonation using industrial waste. Energy Procedia 2011, 4, 1010-1017. [CrossRef]

49. Jandová, J.; Dvorák, P.; Kondás, J.; Havlák, L. Recovery of Lithium from Waste Materials. Ceram.-Silik. 2012, 56, 50-54.

50. Hönisch, B.; Ridgwell, A.; Schmidt, D.N.; Thomas, E.; Gibbs, S.J.; Sluijs, A.; Zeebe, R.; Kump, L.; Martindale, R.C.; Greene, S.E.; et al. The geological record of ocean acidification. Science 2012, 335, 1058-1063. [CrossRef]

51. Haynes, W.M.; Lide, D.R.; Bruno, T.J. CRC handbook of chemistry and physics. In A Ready-Reference Book of Chemical and Physical Data; CRC Press: Boca Raton, FL, USA; London, UK; New York, NY, USA, 2017; ISBN 978-1-4987-5429-3.

52. Yi, W.-T.; Yan, C.-Y.; Ma, P.-H. Kinetic study on carbonation of crude Li2CO3 with CO2-water solutions in a slurry bubble column reactor. Korean J. Chem. Eng. 2011, 28, 703-709. [CrossRef]

53. Yi, W.-T.; Yan, C.-Y.; Ma, P.-H. Crystallization kinetics of $\mathrm{Li}_{2} \mathrm{CO}_{3}$ from $\mathrm{LiHCO}_{3}$ solutions. J. Cryst. Growth 2010, 312, 2345-2350 [CrossRef]

54. Trogdon-Stout, D. Chemistry. In Essential Practice for Key Science Topics; The 100+ Series; Carson Dellosa Publishing Group: Greensboro, NC, USA, 2015; ISBN 1483817091.

55. European Chemicals Agency ECHA. Lithium Carbonate (EC number: 209-062-5 I CAS Number: 554-13-2). Hydrolysis. European Union. 2010. Available online: https:/ / echa.europa.eu/de/registration-dossier/-/registered-dossier/15034/5/2/3\# sLinkToRelevantStudyRecord (accessed on 13 June 2020).

56. Wawra, E.; Dolznig, H.; Müllner, E. Chemie verstehen. In Allgemeine Chemie für Mediziner und Naturwissenschafter, 5. Aufl; UTB: Medizin, Naturwissenschaften, 2009; ISBN 9783825282059.

57. House, J.E. Inorganic Chemistry, 2nd ed.; Elsevier: San Diego, CA, USA, 2020; ISBN 978-0-12-814369-8.

58. Perry, D.L. Handbook of Inorganic Compounds; CRC Press: Hoboken, NJ, USA, 2011; ISBN 978-1-4398-1461-1.

59. Groult, H.; Nakajima, T. Fluorinated Materials for Energy Conversion, 1. Aufl.; Elsevier: Amsterdam, The Netherlands; San Diego, CA, USA; Oxford, UK, 2005; ISBN 9780080444727.

60. Scholz, F.; Kahlert, H. Chemische Gleichgewichte in der Analytischen Chemie; Springer: Berlin/Heidelberg, Germany, 2020; ISBN 978-3-662-61106-7.

61. Binnewies, M.; Finze, M.; Jäckel, M.; Schmidt, P.; Willner, H.; Rayner-Canham, G. Allgemeine und Anorganische Chemie; Springer: Berlin/Heidelberg, Germany, 2016; ISBN 978-3-662-45066-6.

62. Lew, K. Acids and bases. In Essential Chemistry; Chelsea House: New York, NY, USA, 2009; ISBN 9781438116617.

63. Sigma-Aldrich Co. Safety Data Sheet according to Regulation (EC) No. 1907/2006. Lithium Fluoride (CAS-No.: 7789-24-4). 2018. Available online: https://www.sigmaaldrich.com/MSDS/MSDS/DisplayMSDSPage.do?country=DE\&language= EN-generic\&productNumber=449903\&brand=ALDRICH\&PageToGoToURL=https\%3A\%2F\%2Fwww.sigmaaldrich.com \% 2Fcatalog\%2Fsearch\%3Fterm\%3DLiF\%26interface\%3DAll_DE\%26N\%3D0\%26mode\%3Dmatch\%26lang\%3Dde\%26region\% 3DDE\%26focus\%3Dproduct (accessed on 29 December 2020).

64. Shimonishi, Y.; Zhang, T.; Imanishi, N.; Im, D.; Lee, D.J.; Hirano, A.; Takeda, Y.; Yamamoto, O.; Sammes, N. A study on lithium/air secondary batteries-Stability of the NASICON-type lithium ion conducting solid electrolyte in alkaline aqueous solutions. $J$. Power Sources 2011, 196, 5128-5132. [CrossRef] 
65. Bi, X.; Wang, R.; Lu, J. Li-Air Batteries: Discharge products. In Metal-Air Batteries. Fundamentals and Applications; Zhang, X.-B., Ed.; Wiley-VCH: Weinheim, Germany, 2018; ISBN 3527807667.

66. Ham, B.M.; MaHam, A. Analytical chemistry. In A Chemist and Laboratory Technician's Toolkit; John Wiley \& Sons, Inc.: Hoboken, NJ, USA, 2016; ISBN 9781119069690.

67. Zilberman, P. The $\mathrm{CO}_{2}$ Absorber Based on LiOH. Acta Medica Marisiensis 2015, 61, 4-6. [CrossRef]

68. Johnson, G.K.; Grow, R.T.; Hubbard, W.N. The enthalpy of formation of lithium oxide ( $\left.\mathrm{Li}_{2} \mathrm{O}\right)$. J. Chem. Thermodyn. 1975, 7, 781-786. [CrossRef]

69. Li, J.; Wang, G.; Xu, Z. Environmentally-friendly oxygen-free roasting/wet magnetic separation technology for in situ recycling cobalt, lithium carbonate and graphite from spent LiCoO2/graphite lithium batteries. J. Hazard. Mater. 2016, 302, 97-104. [CrossRef] [PubMed]

70. Vishvakarma, S.; Dhawan, N. Recovery of Cobalt and Lithium Values from Discarded Li-Ion Batteries. J. Sustain. Metall. 2019, 5, 204-209. [CrossRef]

71. Xiao, J.; Li, J.; Xu, Z. Recycling metals from lithium ion battery by mechanical separation and vacuum metallurgy. J. Hazard. Mater. 2017, 338, 124-131. [CrossRef]

72. Kuzuhara, S.; Ota, M.; Tsugita, F.; Kasuya, R. Recovering Lithium from the Cathode Active Material in Lithium-Ion Batteries via Thermal Decomposition. Metals 2020, 10, 433. [CrossRef]

73. Wang, J.-P.; Pyo, J.-J.; Ahn, S.-H.; Choi, D.-H.; Lee, B.-W.; Lee, D.-W. A Study on the Recovery of $\mathrm{Li}_{2} \mathrm{CO}_{3}$ from Cathode Active Material NCM(LiNiCoMnO 2$)$ of Spent Lithium Ion Batteries. J. Korean Powder Metall. Inst. 2018, 25, 296-301. [CrossRef]

74. Xiao, J.; Li, J.; Xu, Z. Novel Approach for in Situ Recovery of Lithium Carbonate from Spent Lithium Ion Batteries Using Vacuum Metallurgy. Environ. Sci. Technol. 2017, 51, 11960-11966. [CrossRef]

75. Yang, Y.; Huang, G.; Xu, S.; He, Y.; Liu, X. Thermal treatment process for the recovery of valuable metals from spent lithium-ion batteries. Hydrometallurgy 2016, 165, 390-396. [CrossRef]

76. Lombardo, G.; Ebin, B.; St J Foreman, M.R.; Steenari, B.-M.; Petranikova, M. Incineration of EV Lithium-ion batteries as a pretreatment for recycling-Determination of the potential formation of hazardous by-products and effects on metal compounds. J. Hazard. Mater. 2020, 393, 122372. [CrossRef] [PubMed]

77. Peters, L.; Friedrich, B. Proven Methods for Recovery of Lithium from Spent Batteries; DERA Workshop Lithium: Berlin, Germany, 2017.

78. Petranikova, M. Spracovanie Pouţitých Prenosných Lítiových Akumulátorov. Ph.D. Thesis, Technical University of Košice, Košice, Slovakia, 2012.

79. Mosqueda, H.A.; Vazquez, C.; Bosch, P.; Pfeiffer, H. Chemical Sorption of Carbon Dioxide $\left(\mathrm{CO}_{2}\right)$ on Lithium Oxide (Li $\left.2 \mathrm{O}\right)$. Chem. Mater. 2006, 18, 2307-2310. [CrossRef]

80. Ueda, S.; Inoue, R.; Sasaki, K.; Wakuta, K.; Ariyama, T. $\mathrm{CO}_{2}$ Absorption and Desorption Abilities of $\mathrm{Li}_{2} \mathrm{O}-\mathrm{TiO}_{2}$ Compounds. ISIJ Int. 2011, 51, 530-537. [CrossRef]

81. Sloop, S.E.; Parker, R. System and Method for Processing an End-of-Life or Reduced Performance Energy Storage and/or Conversion Device Using a Supercritical Fluid (US 8,067,107 B2). 2011. Available online: https:/ / patentimages.storage.googleapis. com/1f/5d/1b/69963cd0c16466/US8067107.pdf (accessed on 1 April 2020).

82. Nowak, S.; Winter, M. The Role of Sub- and Supercritical $\mathrm{CO}_{2}$ as "Processing Solvent" for the Recycling and Sample Preparation of Lithium Ion Battery Electrolytes. Molecules 2017, 22, 403. [CrossRef]

83. Chen, Y.; Tian, Q.; Chen, B.; Shi, X.; Liao, T. Preparation of lithium carbonate from spodumene by a sodium carbonate autoclave process. Hydrometallurgy 2011, 109, 43-46. [CrossRef]

84. Bertau, M.; Voigt, W.; Schneider, A.; Martin, G. Lithiumgewinnung aus anspruchsvollen Lagerstätten: Zinnwaldit und magnesiumreiche Salzseen. Chem. Ing. Tech. 2017, 89, 64-81. [CrossRef]

85. Liu, Y. Analysis on Extraction Behaviour of Lithium-ion Battery Electrolyte Solvents in Supercritical $\mathrm{CO}_{2}$ by Gas Chromatography. Int. J. Electrochem. Sci. 2016, 11, 7594-7604. [CrossRef]

86. Grützke, M.; Mönnighoff, X.; Horsthemke, F.; Kraft, V.; Winter, M.; Nowak, S. Extraction of lithium-ion battery electrolytes with liquid and supercritical carbon dioxide and additional solvents. RSC Adv. 2015, 5, 43209-43217. [CrossRef]

87. Rothermel, S.; Grützke, M.; Mönnighoff, X.; Winter, M.; Nowak, S. Electrolyte Extraction—Sub and Supercritical $\mathrm{CO}_{2}$. In Recycling of Lithium-Ion Batteries; Kwade, A., Diekmann, J., Eds.; Springer International Publishing: Cham, Switzerland, 2018; pp. 177-185, ISBN 978-3-319-70571-2.

88. Sloop, S.; Crandon, L.; Allen, M.; Koetje, K.; Reed, L.; Gaines, L.; Sirisaksoontorn, W.; Lerner, M. A direct recycling case study from a lithium-ion battery recall. Sustain. Mater. Technol. 2020, 25, e00152. [CrossRef]

89. Rothermel, S.; Evertz, M.; Kasnatscheew, J.; Qi, X.; Grützke, M.; Winter, M.; Nowak, S. Graphite Recycling from Spent Lithium-Ion Batteries. ChemSusChem 2016, 9, 3473-3484. [CrossRef] [PubMed]

90. Bertau, M.; Martin, G. Integrated Direct Carbonation Process for Lithium Recovery from Primary and Secondary Resources. Mater. Sci. Forum 2019, 959, 69-73. [CrossRef]

91. Bertau, M.; Martin, G.; Pätzold, C. Verfahren zur Gewinnung von Lithiumcarbonat aus lithiumhaltigen Batterierückständen mittels CO2-Behandlung. Deutsche Patentanmeldung (DE102016208407A1), 23 November 2017.

92. Stopic, S.; Dertmann, C.; Koiwa, I.; Kremer, D.; Wotruba, H.; Etzold, S.; Telle, R.; Knops, P.; Friedrich, B. Synthesis of Nanosilica via Olivine Mineral Carbonation under High Pressure in an Autoclave. Metals 2019, 9, 708. [CrossRef] 
93. Peled, E.; Golodnitsky, D.; Penciner, J. The Anode/Electrolyte Interface. In Handbook of Battery Materials, 2. Aufl.; Daniel, C., Besenhard, J.O., Eds.; Wiley-VCH: Weinheim, Germany, 2012; pp. 479-524, ISBN 978-3-527-32695-2. 